\title{
Impact of bacteria on the phenotype, functions, and therapeutic activities of invariant NKT cells in mice
}

\author{
Sungjune Kim, Saif Lalani, Vrajesh V. Parekh, Tiffaney L. Vincent, Lan Wu, and Luc Van Kaer \\ Department of Microbiology and Immunology, Vanderbilt University School of Medicine, Nashville, Tennessee, USA.
}

\begin{abstract}
Invariant NKT (iNKT) cells are innate-like lymphocytes that recognize glycolipid antigens in the context of the MHC class I-like antigen-presenting molecule CD1d. In vivo activation of mouse iNKT cells with the glycolipid $\alpha$-galactosylceramide ( $\alpha$-GalCer) results in the acquisition of a hyporesponsive (anergic) phenotype by these cells. Because iNKT cells can become activated in the context of infectious agents, here we evaluated whether iNKT cell activation by microorganisms can influence subsequent responses of these cells to glycolipid antigen stimulation. We found that mouse iNKT cells activated in vivo by multiple bacterial microorganisms, or by bacterial LPS or flagellin, became unresponsive to subsequent activation with $\alpha-G a l C e r$. This hyporesponsive phenotype of iNKT cells required IL-12 expression and was associated with changes in the surface phenotype of these cells, reduced severity of concanavalin A-induced hepatitis, and alterations in the therapeutic activities of $\alpha$-GalCer. These findings may have important implications for the development of iNKT cell-based therapies.
\end{abstract}

\section{Introduction}

NKT cells are unique T lymphocytes that coexpress TCRs and NK cell markers (1-6). Most NKT cells, referred to as invariant NKT (iNKT) cells, express a semi-invariant TCR consisting of a V $\alpha 14$ J $\alpha 18$ chain paired predominantly with a V $\beta 8.2$ chain in mice (7). Unlike conventional $\mathrm{T}$ cells, which recognize peptides presented by MHC class I or class II proteins, iNKT cells are specific for glycolipid antigens presented by the MHC class I-related protein CD1d. In response to TCR engagement, iNKT cells can rapidly produce a variety of cytokines, and hence these cells can impart potent immunoregulatory properties. Thus, iNKT cells can promote protective immune responses against infectious agents, suppress autoimmunity, promote natural tumor immunity, and regulate allergic airway inflammation, atherosclerosis, colitis, and contact hypersensitivity in mice.

The physiological antigens that are recognized by iNKT cells remain incompletely understood (8). All iNKT cells react with the glycosphingolipid $\alpha$-galactosylceramide ( $\alpha$-GalCer), which was originally isolated from a marine sponge. More recently, it has been demonstrated that iNKT cells can react with $\alpha$-anomeric glycosphingolipids derived from the cell wall of Gram-negative Sphingomonas bacteria (9-11) and with $\alpha$-galactosyl diacylglycerols from the spirochete Borrelia burgdorferi (12), the etiologic agent of Lyme disease. However, the endogenous ligands for iNKT cells remain to be fully characterized (13).

The immunomodulatory properties of iNKT cells have been exploited for the development of immunotherapies $(1-3,5,14)$. In most of these studies, derivatives of $\alpha$-GalCer have been employed. $\alpha$-GalCer potently activates iNKT cells to secrete a mixture of Th1

Nonstandard abbreviations used: B6, C57BL/6 [mice]; ConA, concanavalin A; $\alpha$-GalCer, $\alpha$-galactosylceramide; iNKT, invariant NKT; LCMV, lymphocytic choriomeningitis virus; PerCP, peridinin chlorophyll protein.

Conflict of interest: The authors have declared that no conflict of interest exists. Citation for this article: J. Clin. Invest. 118:2301-2315 (2008). doi:10.1172/JCI33071. and Th2 cytokines. iNKT cells activated in this manner transactivate a variety of other cell types, including APCs, NK cells, and conventional $\mathrm{T}$ and $\mathrm{B}$ cells (15). The potent immunostimulatory activities of $\alpha$-GalCer on APCs, in particular DCs, have been exploited for the development of vaccine adjuvants. In addition, repeated injection of $\alpha$-GalCer can prevent development of tumor metastases and Th1-dominant autoimmunity in mice $(1-3,5,14)$.

A thorough understanding of iNKT cell responses to various stimuli is important in order to develop effective iNKT cell-based adjuvants and immunotherapies for human disease. Prior studies have shown that a single injection of $\alpha$-GalCer to mice results in rapid iNKT cell activation and cytokine production. This activation also results in transient downregulation of the invariant TCR and sustained downregulation of the NK cell marker NK1.1 on iNKT cells (16-18). In vivo-activated iNKT cells rapidly proliferate, leading to profound expansion of this cell population in multiple organs, which peaks around 3 days after $\alpha$-GalCer treatment. This period of rapid iNKT cell expansion is followed by a contraction phase mediated by homeostatic mechanisms. Importantly, restimulation of these $\alpha$-GalCer-experienced iNKT cells with $\alpha$-GalCer results in a suppressed response because the iNKT cells acquire an anergic phenotype (19-22). iNKT cell anergy induced in this manner is maintained for at least 1 month. Additional studies showed that iNKT cell anergy has a profound impact on iNKT cell-mediated functions and the therapeutic properties of $\alpha$-GalCer (19).

iNKT cell activation has been observed in the context of glycolipid antigens, cytokines, multiple microorganisms, and inflammatory stimuli $(1-3,23,24)$. In the case of certain microorganisms, such as Sphingomonas and Borrelia, iNKT cell activation involves specific, pathogen-derived glycolipid antigens. For many other microorganisms, however, there is no evidence for direct iNKT cell activation by microbial glycolipid antigens. Instead, many microorganisms might activate iNKT cells in a nonspecific manner, by stimulating the production of proinflammatory cytokines by DCs that can activate iNKT cells by themselves, in concert with 
A
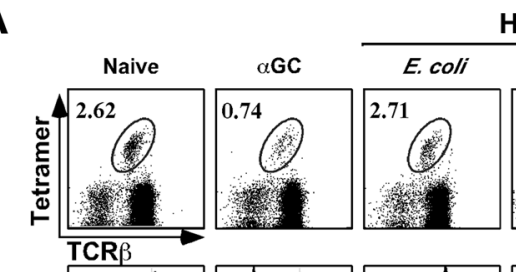

Heat-killed
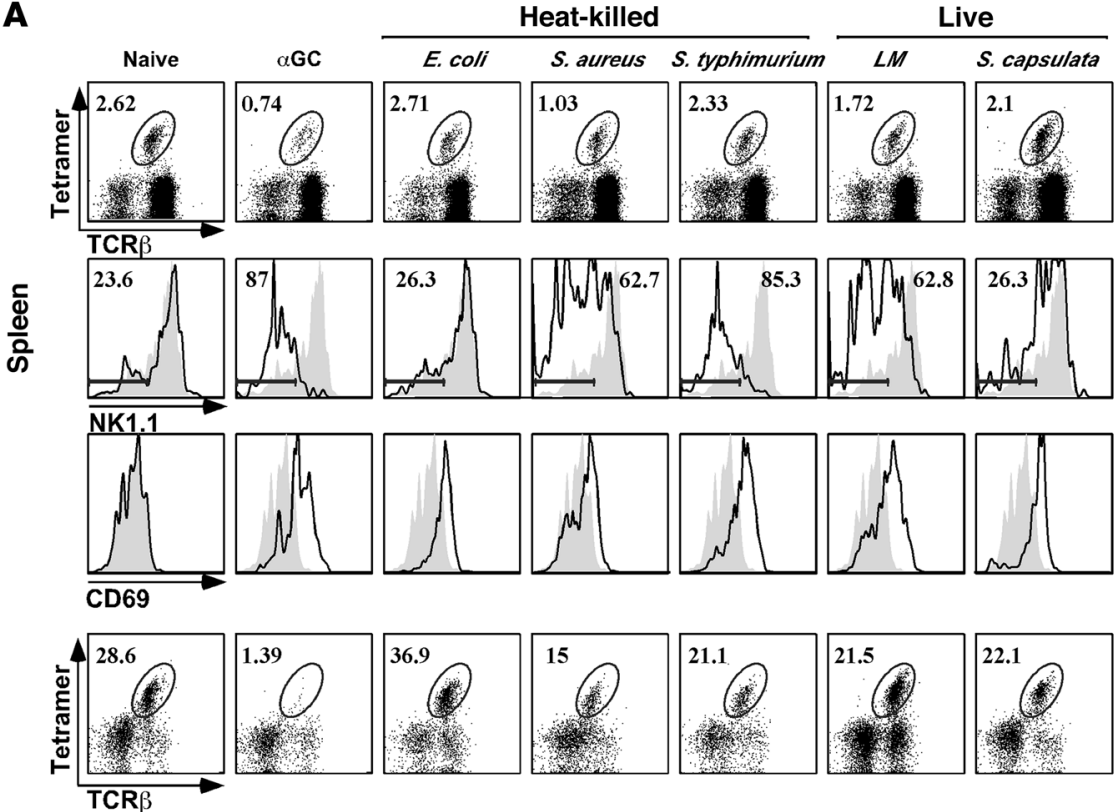

$\stackrel{\bar{\Xi}}{\stackrel{亠}{\Xi}}$
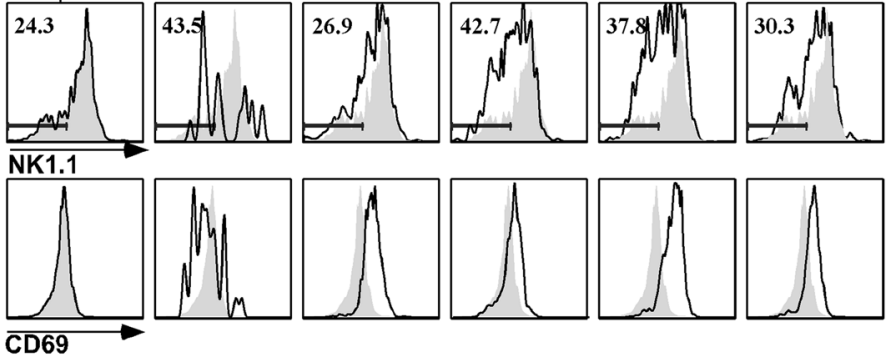

B
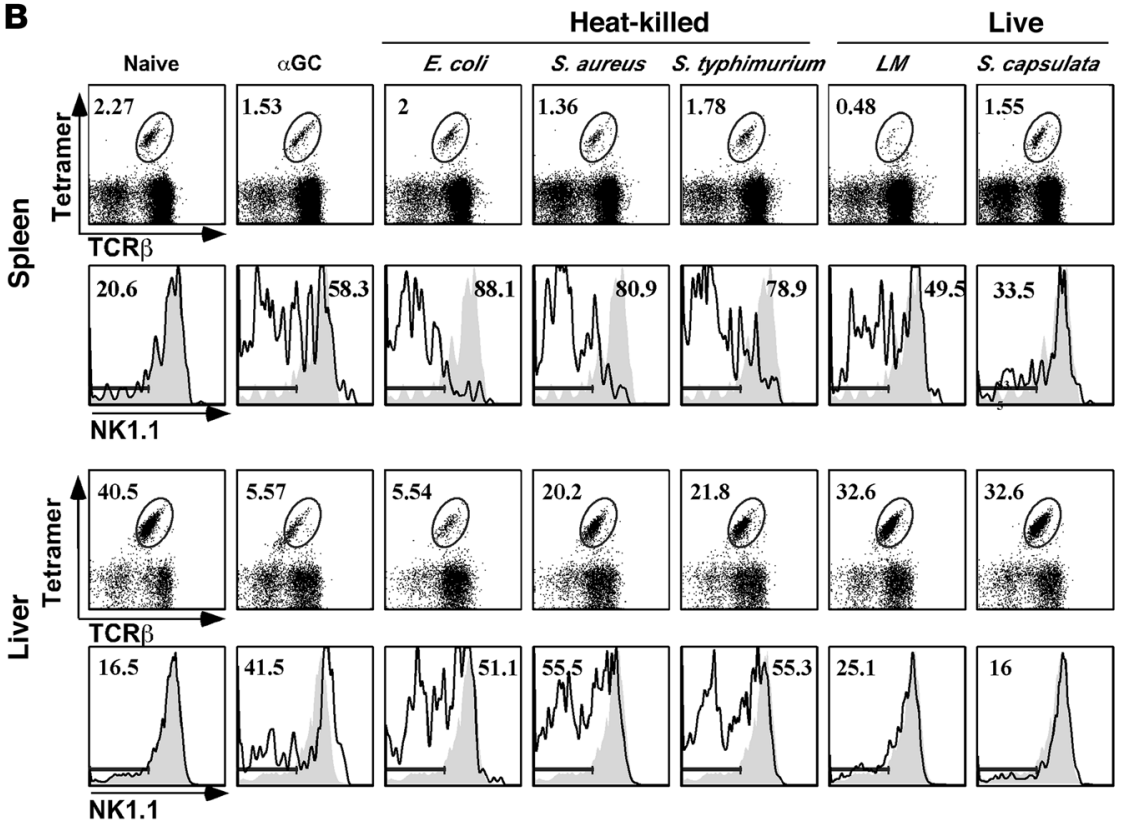

endogenous glycolipid antigens, or by inducing CD1d expression on APCs $(10,25-27)$. Whether iNKT cell activation by microorganisms influences subsequent responses of these cells to antigenic stimulation remains unclear. Here we report results demonstrating that bacteria have a profound impact on the functional status
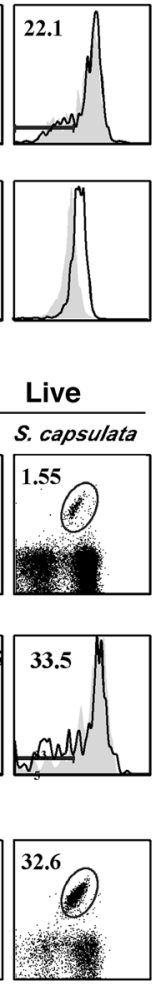

\section{Figure 1}

Multiple bacterial microorganisms activate murine iNKT cells, resulting in hyporesponsiveness of splenocytes to subsequent in vitro challenge with $\alpha$-GalCer $(\alpha \mathrm{GC})$. In vivo response of mice to treatment with heat-killed or live bacteria at day 1 (A) or week $3(\mathbf{B})$. Mice were injected with $\alpha$-GalCer ( $5 \mu \mathrm{g} / \mathrm{mouse}$, i.p.) or with the indicated heat-killed or live bacteria (i.v.) and sacrificed at day 1 or week 3 , and spleen or liver mononuclear cells were prepared and stained with anti-TCR- $\beta$-FITC, anti-CD69-FITC, antiNK1.1-PE, anti-B220-PerCP, and CD1d-tetramer-APC and analyzed by flow cytometry. Numbers indicate the percentage of TCR- $\beta^{+}$tetramer ${ }^{+}$ cells among B220- cells or the percentage of NK1.1- cells among iNKT cells. The shaded areas represent the staining of naive iNKT cells, and the solid lines represent the staining of iNKT cells from mice treated with $\alpha$-GalCer or bacteria. Representative plots from 4-8 mice per group are shown. $L M, L$. monocytogenes.

of iNKT cells with long-term effects on the therapeutic activities of these cells.

\section{Results}

Mouse iNKT cells become activated in vivo by diverse bacterial species. Prior studies have shown that iNKT cells can become activated in response to various infectious agents, either through direct recognition of microbial glycolipid antigen or indirectly through cytokines secreted by DCs in conjunction with endogenous antigens expressed by activated DCs (23). We tested the capacity of a wide variety of bacteria, including the Grampositive organisms Listeria monocytogenes and Staphylococcus aureus and the Gram-negative organisms E. coli, Salmonella typhimurium, and Sphingomonas capsulata to activate iNKT cells and to modulate the functions of these cells. As we were primarily interested in the longterm effects of bacterial microorganisms on iNKT cell functions, the choice of bacteria was not limited to known pathogens that depend on iNKT cells for their clearance. Apart from L. monocytogenes and S. capsulata, bacteria were heat killed prior to challenge. Activation of iNKT cells was assessed by their prevalence and numbers and by their surface phenotype, such as expression of CD69, an early activation marker, and NK1.1, which becomes downregulated on activated iNKT cells $(16,17)$ and remains expressed at low levels on iNKT cells rendered anergic in $\alpha$-GalCer-treated animals (19). Analyses were performed 24 hours after i.v. injection of bacteria. Naive mice and mice injected with $5 \mu \mathrm{g} \alpha$-GalCer were used as controls.

Consistent with prior studies (16-18), 24 hours after $\alpha$-GalCer injection, TCR downregulation rendered iNKT cells undetectable 

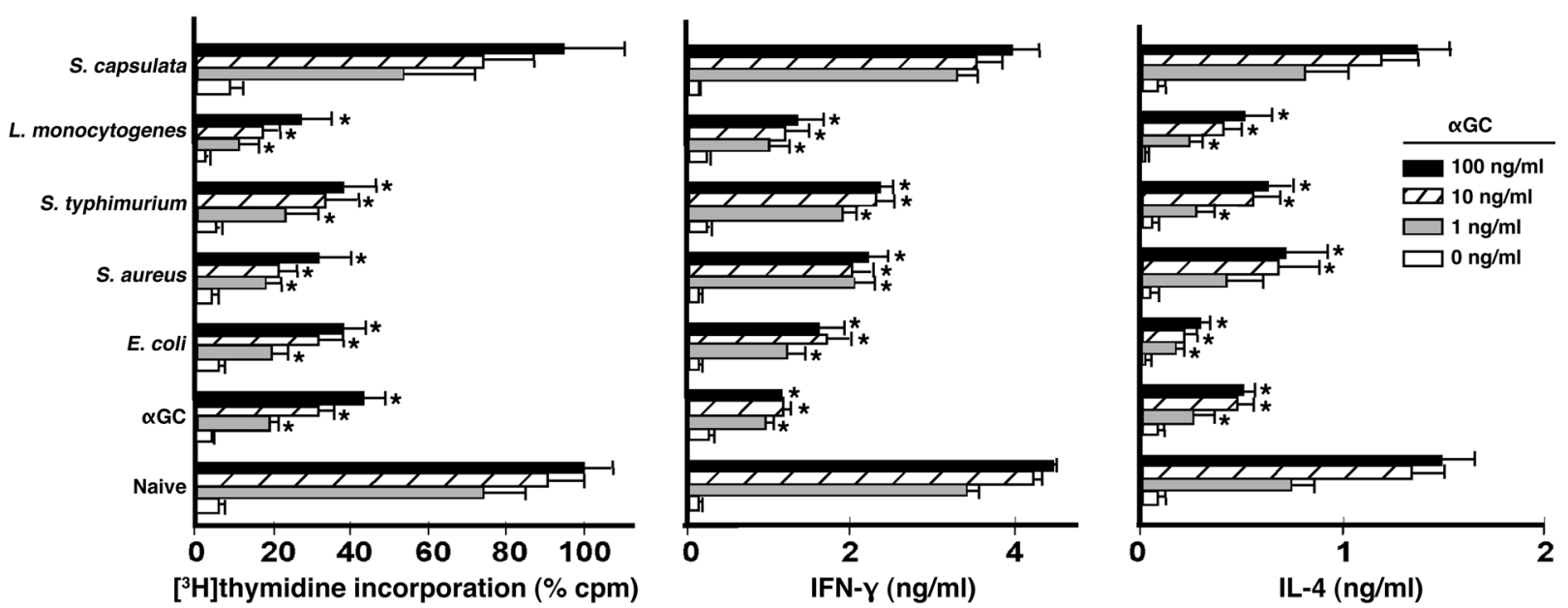

Figure 2

The in vitro response of splenocytes to $\alpha$-GalCer from mice treated 3 weeks earlier with $\alpha$-GalCer or bacteria. Mice were injected with $\alpha$-GalCer $\left(5 \mu \mathrm{g} /\right.$ mouse, i.p.) or the indicated bacteria and sacrificed 3 weeks later, and splenocytes $\left(2 \times 10^{5}\right.$ per well) were cultured with graded doses of $\alpha$-GalCer. After 3 days, proliferation was assessed by $\left[{ }^{3} \mathrm{H}\right]$ thymidine incorporation, and culture supernatants were evaluated for IL-4 and IFN- $\gamma$ levels by ELISA. Proliferation and cytokine results represent the mean \pm SEM of 6-11 mice per group, pooled from 3 experiments. ${ }^{*} P<0.05$ compared with naive splenocytes cultured with the same dose of $\alpha$-GalCer.

by tetramer staining (Figure 1A). Minor decreases in iNKT cell numbers were observed in the spleens of mice injected with L. monocytogenes and S. aureus and in livers of mice injected with L. monocytogenes, S. aureus, S. capsulata, and S. typhimurium. Differences in iNKT cell numbers in the liver reached statistical significance $(P<0.05)$ only after L. monocytogenes and S. capsulata injections.

Each of the bacterial organisms tested induced upregulation of CD69 on iNKT cells, suggesting activation of these cells. However, the extent of CD69 upregulation was variable, reflecting potential differences in the degree or kinetics of iNKT cell activation induced by distinct organisms. NK1.1 downregulation by spleen iNKT cells was observed for heat-killed S. aureus, S. typhimurium, and live L. monocytogenes but was less evident for heat-killed E. coli and live S. capsulata. The changes observed in hepatic iNKT cells mirrored changes in splenic iNKT cells, except for downregulation of NK1.1, which was only evident for S. aureus and S. typhimurium (Figure 1A).

Next, we examined the prevalence, cell number, and surface phenotype of iNKT cells 3 weeks after injection of $\alpha$-GalCer or bacteria. Consistent with prior studies (19), $\alpha$-GalCer injection resulted in a modest decrease in the frequency of iNKT cells in the spleen and liver, accompanied by sustained NK1.1 downregulation in spleen (Figure 1B). Similar changes were observed in mice that received heat-killed E. coli, S. aureus, or S. typhimurium. Notably, inoculation of live L. monocytogenes resulted in a substantial loss of iNKT cells and sustained downregulation of NK1.1. By contrast, $S$. capsulata did not induce sustained changes in the surface phenotype of iNKT cells.

In summary, all bacteria tested were able to induce early activation of iNKT cells, but the changes in surface phenotype of these cells induced by different bacteria were distinct and were different from the phenotype of iNKT cells induced by $\alpha$-GalCer.

Impact of bacteria-induced $i N K T$ cell activation in vivo on the response of splenocytes to subsequent $\alpha$-GalCer stimulation ex vivo. Prior studies have demonstrated that $\alpha$-GalCer treatment of mice results in long-term suppression of subsequent iNKT cell responses to $\alpha$ GalCer ex vivo and in vivo (19-21). Several of the bacteria tested activated and induced phenotypic alterations in iNKT cells that were characteristic of anergic iNKT cells induced in response to $\alpha$-GalCer treatment (Figure 1, A and B). Therefore, we treated mice with heat-killed or live bacteria, and 3 weeks later we measured responses of splenocytes from these animals to stimulation with $\alpha$-GalCer. Consistent with prior studies (19-21), splenocytes from $\alpha$-GalCer-injected mice showed dampened proliferation and cytokine production as compared with naive splenocytes (Figure 2). Interestingly, splenocytes from mice injected with heat-killed E. coli, S. aureus, or S. typhimurium or with live L. monocytogenes also showed significant defects in proliferation and cytokine production in response to subsequent ex vivo stimulation of iNKT cells with $\alpha$-GalCer (Figure 2). For most of these bacteria, there was a trend toward a more profound defect in IL- 4 than IFN- $\gamma$ production by hyporesponsive iNKT cells, whereas iNKT cells rendered anergic by $\alpha$-GalCer had a more profound defect in IFN- $\gamma$ than IL-4 production (Figure 2 and ref. 19). In sharp contrast to the effect on iNKT cell responses, bacteria did not alter conventional $\mathrm{T}$ cell function (see below and Supplemental Figure 1; supplemental material available online with this article; doi:10.1172/ JCI33071DS1). Collectively, our findings suggest that bacteria can impair iNKT cell functions in vivo.

Kinetics of iNKT cell responses in mice treated with heat-killed E. coli or live L. monocytogenes. We selected 2 organisms, heat-killed E. coli and live L. monocytogenes, which showed the strongest effects on iNKT cell responses, to perform a detailed characterization of the kinetics of iNKT cell responses. We measured iNKT cell numbers, expansion, surface phenotype, and functions at different time points after treatment.

After treatment with heat-killed E. coli, there was a modest decrease in total numbers of splenic iNKT cells over time (Figure 3 , A and B), but this did not reach statistical significance. The frequency of liver iNKT cells, on the other hand, dropped between 3 and 4 weeks, which was due to an influx of conventional $\mathrm{T}$ cells into the liver (data not shown), but the prevalence of iNKT cells returned to relatively normal levels around 6 weeks. NK1.1 sur- 
A
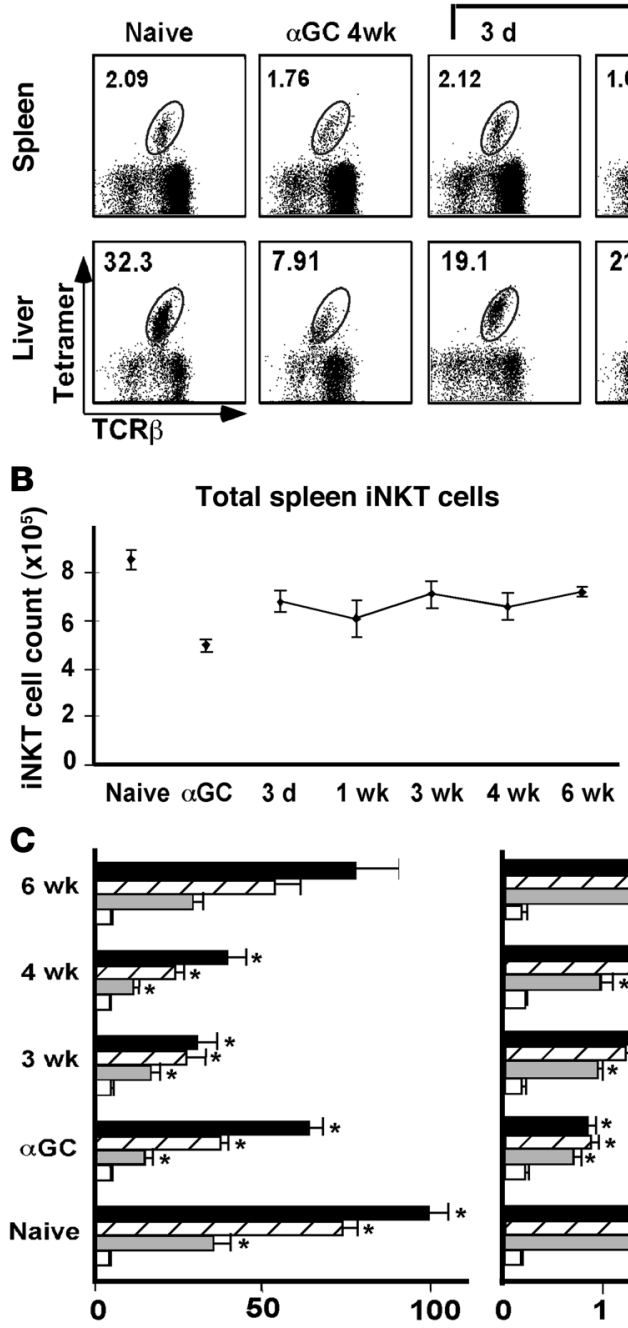

$\left[{ }^{3} \mathrm{H}\right]$ thymidine incorporation (\% cpm)
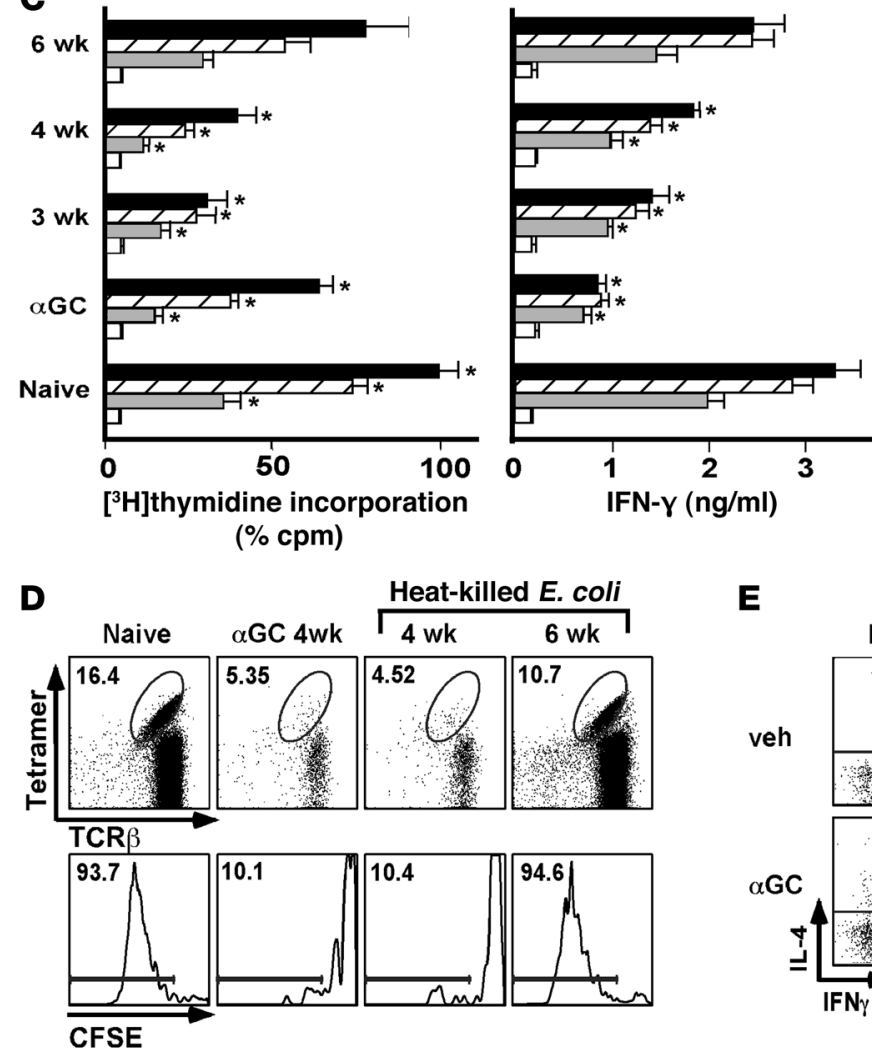
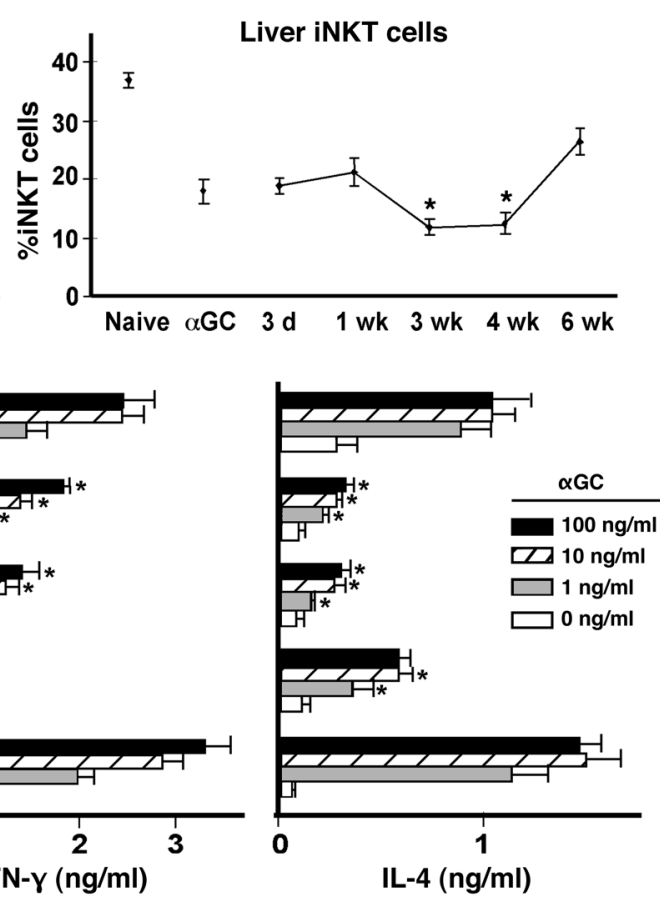

Heat-killed E. coli
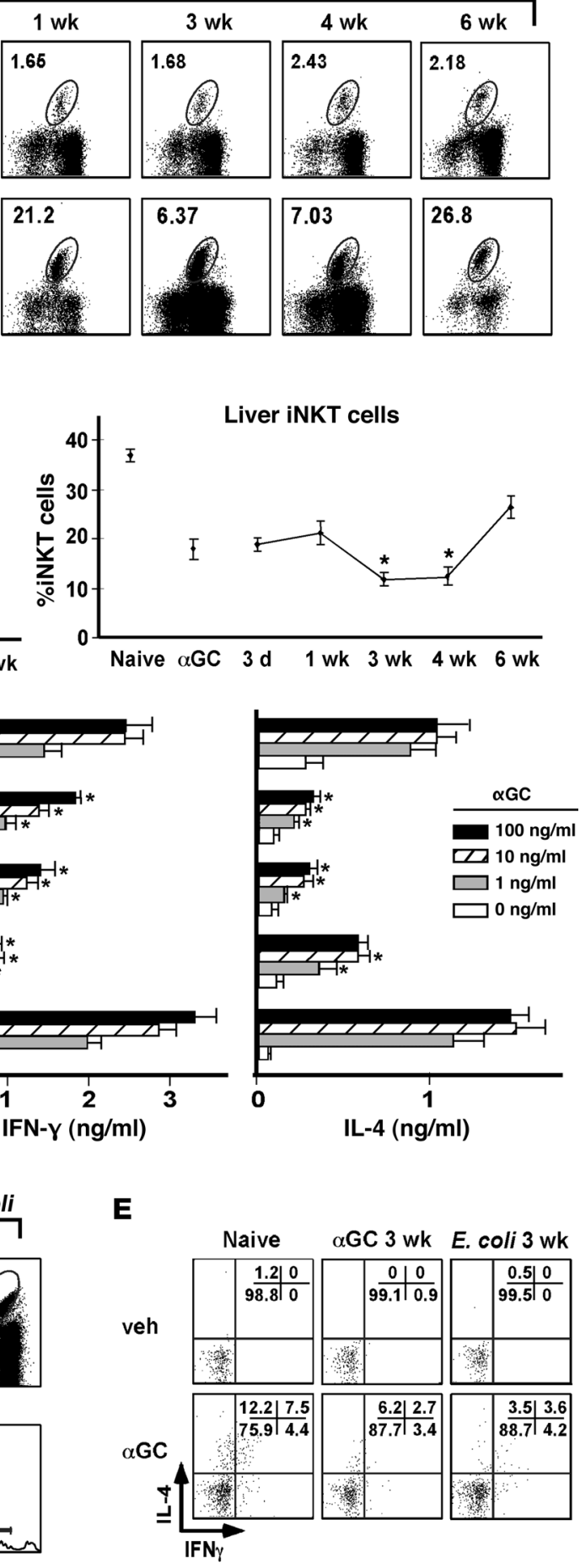

Figure 3

Heat-killed E. coli induces hyporesponsiveness of iNKT cells to $\alpha$-GalCer rechallenge ex vivo. (A) In vivo dynamics of the iNKT cell response. Mice were injected with $\alpha$-GalCer (5 $\mu \mathrm{g} /$ mouse, i.p.) or heat-killed $E$. coli and sacrificed at the indicated time points, and spleen and liver mononuclear cells were prepared and stained for the identification of iNKT cells. (B) Total spleen iNKT cell counts and percentage of liver iNKT cells at the indicated times, for a total of 5-10 mice per group, pooled from 2 separate experiments. ${ }^{*} P<0.05$ compared with naive animals. (C) $\alpha$-GalCer recall response of mice at the indicated times after treatment with heat-killed $E$. coli. Mice were injected with $\alpha$-GalCer or heat-killed $E$. coli and sacrificed 3,4 , or 6 weeks later, and splenocytes were cultured with graded doses of $\alpha$-GalCer. After 3 days, proliferation was assessed, and culture supernatants were evaluated for IL-4 and IFN- $\gamma$. ${ }^{*} P<0.05$ compared with naive splenocytes. (D) Proliferative defect in iNKT cells from mice treated with heatkilled $E$. coli. Spleen cells from naive mice or from mice injected 4 or 6 weeks earlier with $\alpha$-GalCer or heat-killed $E$. coli were labeled with CFSE. Cells were then cultured with $\alpha$-GalCer $(100 \mathrm{ng} / \mathrm{ml})$ for 24 hours, then washed and cultured for an additional 96 hours without $\alpha$-GalCer. At the end of the culture period, cells were harvested, stained, and analyzed by flow cytometry. (E) iNKT cell cytokine production. Spleen cells were prepared at the indicated time points, and cells were cultured for 6 hours in vehicle or $100 \mathrm{ng} / \mathrm{ml} \alpha$-GalCer in the presence of GolgiPlug. Cells were then harvested and stained. face levels became downregulated in the spleen and liver around 2-3 weeks, returned to normal levels in the liver by week 6 , but remained suppressed in the spleen until week 6 (Supplemental Figure 2A). We also observed a modest decrease in the expression of the NK cell receptor NKG2D and the CD94 subunit of the NKG2/CD94 family of NK cell receptors but no alterations in the levels of Ly49 receptors (Supplemental Figure 3). Analysis of iNKT cell responses revealed suppressed capacity of splenocytes to proliferate and produce IFN- $\gamma$ and IL-4 upon in vitro stimulation with $\alpha$-GalCer at 3 and 4 weeks after treatment with heat-killed $E$. coli (Figure 3C). In E. coli-treated mice, in contrast to $\alpha$-GalCer-injected controls, the blockade in IL-4 production appeared to be more profound than that in IFN- $\gamma$ production. Despite sustained NK1.1 downregulation on iNKT cells, splenocytes generated relatively 
A
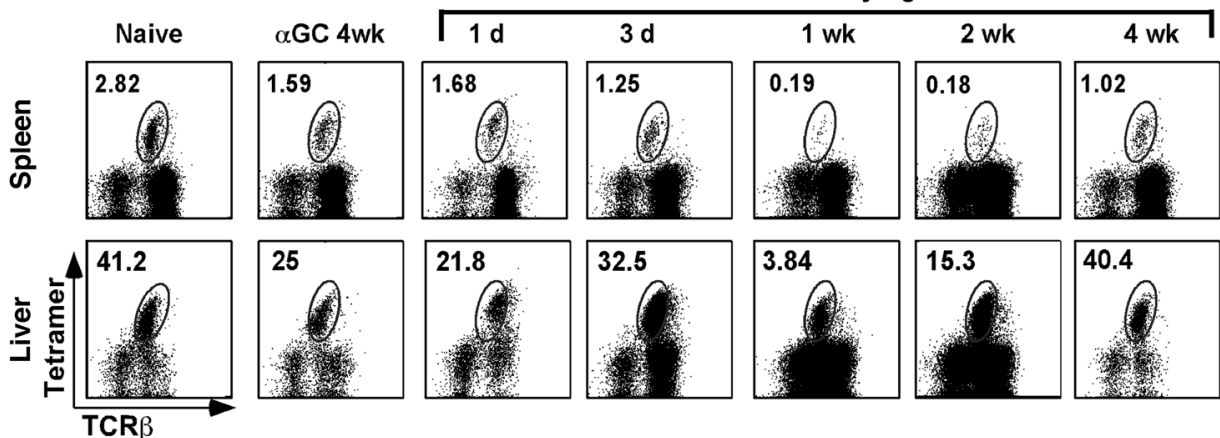

40.4

B
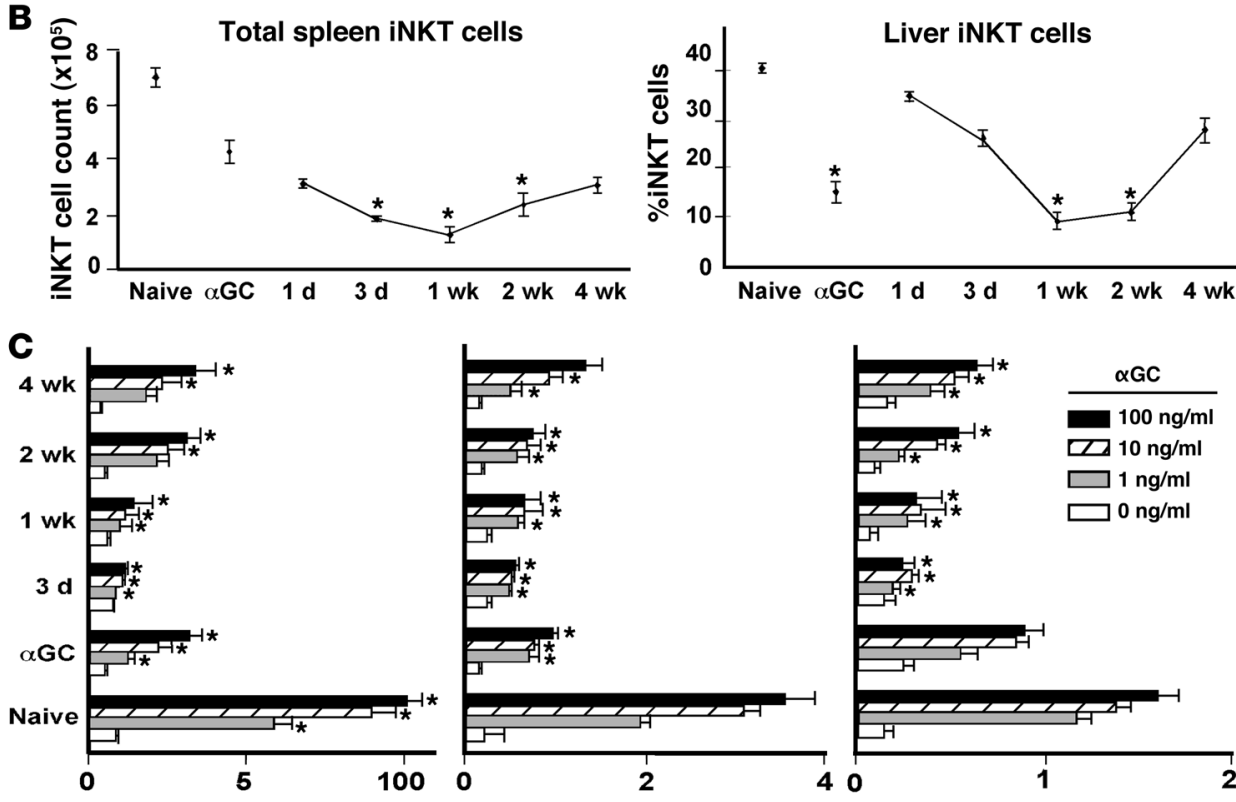

$\left[{ }^{3} \mathrm{H}\right]$ thymidine incorporation (\% cpm)
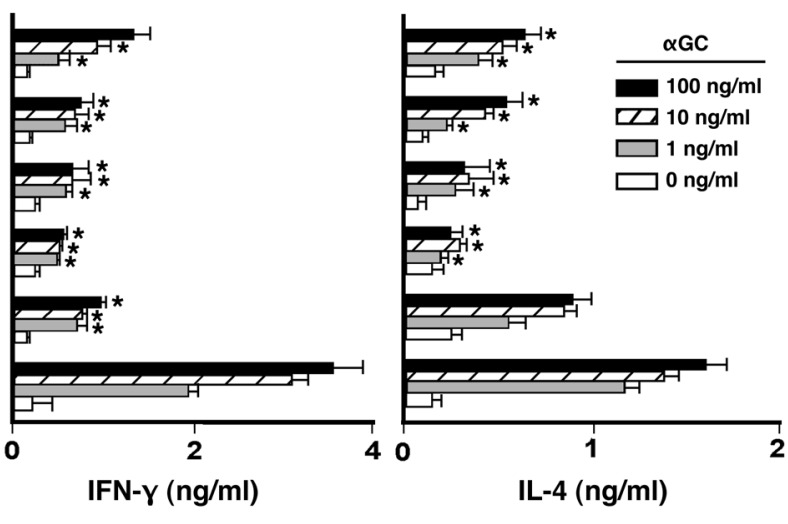

D

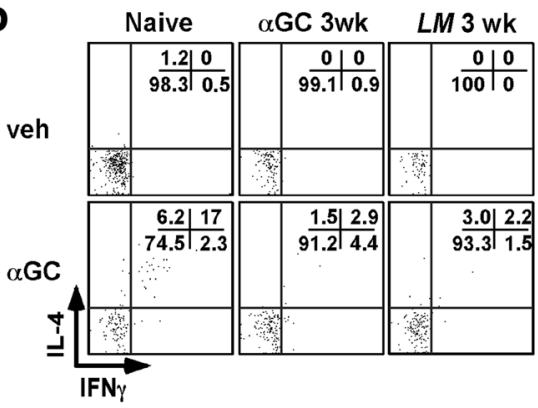

Figure 4

Live L. monocytogenes infection induces hyporesponsiveness of iNKT cells to $\alpha$-GalCer rechallenge ex vivo. (A) In vivo dynamics of the iNKT cell population in response to $L$. monocytogenes infection. Mice were injected with $\alpha$-GalCer $(5 \mu \mathrm{g} /$ mouse, i.p.) or infected with L. monocytogenes and sacrificed at the indicated time points, and spleen and liver mononuclear cells were prepared and stained with anti-TCR- $\beta-$ FITC, anti-NK1.1-PE, anti-B220-PerCP, and tetramer-allophycocyanin. Numbers indicate the percentage of TCR- $\beta^{+}$ tetramer ${ }^{+}$cells among B220- cells. Representative plots from 4-7 mice per group are shown. (B) Total spleen iNKT cell counts and percentage of liver iNKT cells at the indicated times, for a total of 4-7 mice per group, pooled from 2 separate experiments. ${ }^{*} P<0.05 \mathrm{com}$ pared with naive animals. (C) The in vitro $\alpha$-GalCer recall response of mice at the indicated times after infection. Mice were infected with $L$. monocytogenes and sacrificed 3 days or 1 , 2, or 4 weeks later, and splenocytes $\left(2 \times 10^{5}\right.$ per well) were cultured with graded doses of $\alpha$-GalCer. After 3 days, proliferation was assessed by $\left[{ }^{3} \mathrm{H}\right]$ thymidine incorporation, and culture supernatants were evaluated for IL-4 and IFN- $\gamma$ levels by ELISA. Proliferation and cytokine results represent the mean \pm SEM of 4-8 mice pooled from 2 separate experiments. ${ }^{*} P<0.05$ compared with naive splenocytes cultured with the same dose of $\alpha$-GalCer. (D) iNKT cell cytokine production. Spleen cells were prepared at the indicated times, and $2 \times 10^{5}$ cells were cultured for 6 hours in plain medium or $100 \mathrm{ng} / \mathrm{ml} \alpha$-GalCer in the presence of GolgiPlug. Cells were then harvested and surface stained with tetramer-PE and anti-B220-PerCP, followed by intracellular staining with anti-IFN- $\gamma$-FITC and anti-IL-4-allophycocyanin. Data are shown for B220 tetramer ${ }^{+}$cells. Numbers indicate the percentage of cells within each quadrant. Results shown are representative of 2 independent experiments. normal responses to E. coli by week 6 . To assess effects on iNKT cell proliferation and cytokine production more directly, we performed CFSE dilution and intracellular staining experiments. Results demonstrated reduced capacity of iNKT cells from E. coli-treated animals to proliferate (Figure 3D) and to produce cytokines (Figure $3 \mathrm{E}$ ) in response to $\alpha$-GalCer stimulation ex vivo.

Treatment of mice with live L. monocytogenes, in contrast to heatkilled $E$. coli and $\alpha$-GalCer, resulted in a dramatic reduction in iNKT cell frequency and numbers in both spleen and liver (Figure 4, A and B). By week 4, numbers of iNKT cells had recovered in the liver but not spleen. The NK1.1 expression pattern following infec- tion with $L$. monocytogenes closely mimicked that seen after $\alpha$-GalCer treatment (Supplemental Figure 2B). NK1.1 downregulation was evident by day 1 and persisted until week 4 . These alterations in iNKT cell numbers were accompanied by profound changes in the response of splenocytes to $\alpha$-GalCer stimulation (Figure 4C). In addition, intracellular staining revealed reduced capacity of iNKT cells from $L$. monocytogenes-infected animals to produce cytokines in response to $\alpha$-GalCer stimulation ex vivo (Figure 4D).

Bacteria induce long-term iNKT cell hyporesponsiveness in vivo. To determine whether bacteria can modulate iNKT cell responses in vivo, we injected mice with heat-killed E. coli, S. aureus, or 
A

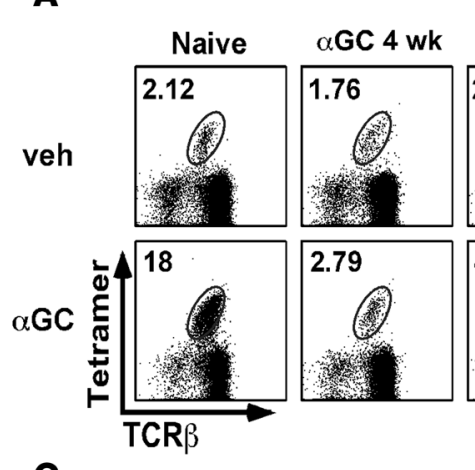

C

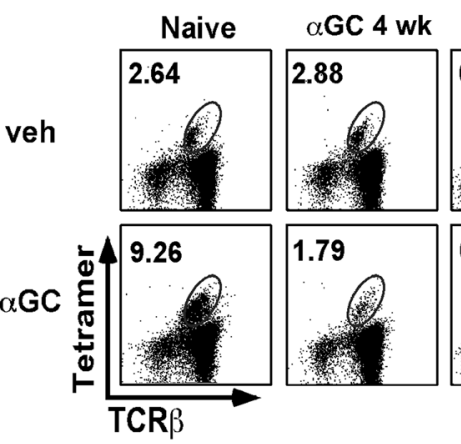

E
veh

veh

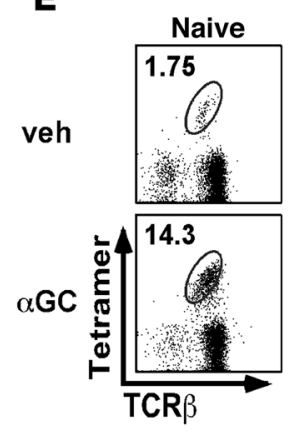

G

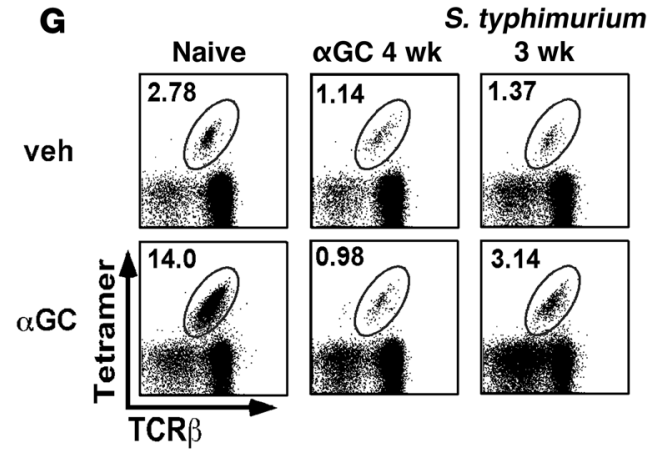

E. coli

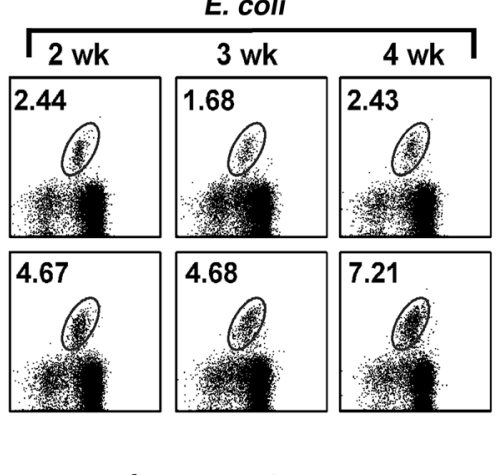

L. monocytogenes
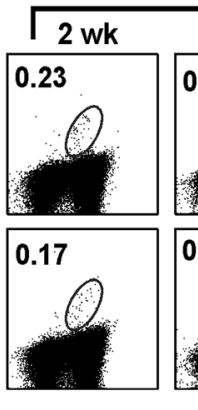

S. aureus

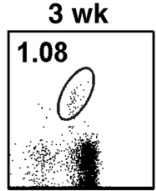

2.78

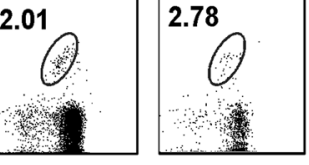

31

$3 \mathrm{wk} 4 \mathrm{wk}$

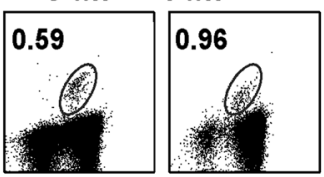

$0.75 \quad 1.01$

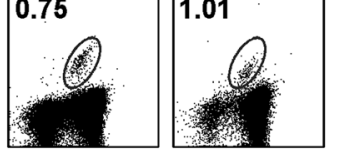

$\mathbf{F}$
B

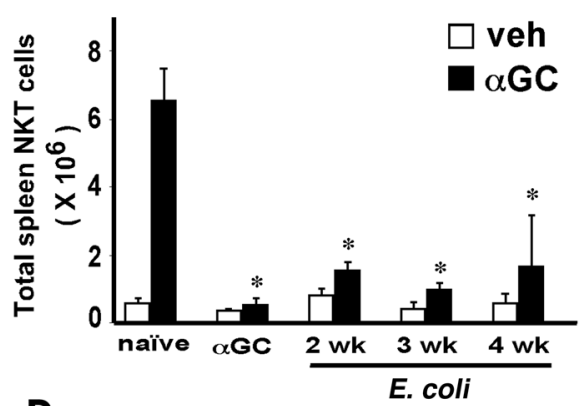

D

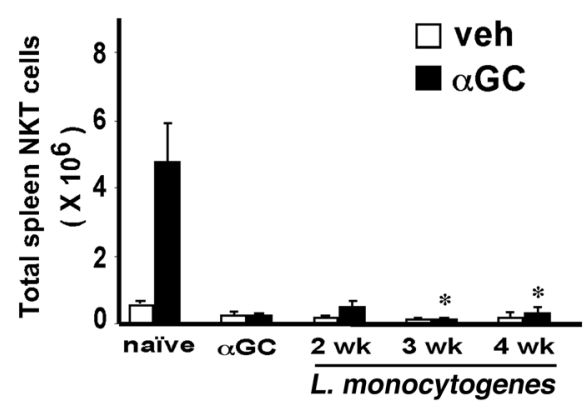

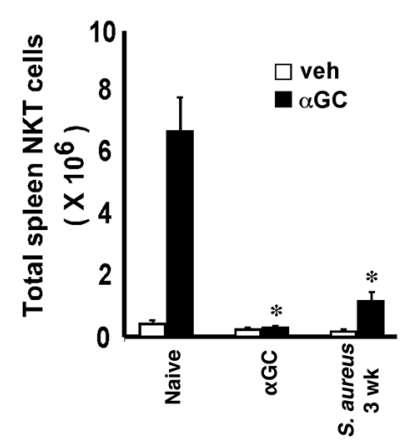

H

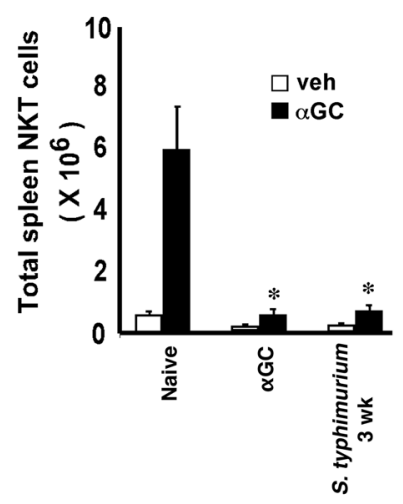

I $\alpha G C 3$ wk E. coli 3 wk LM 3 wk pretreated pretreated pretreated

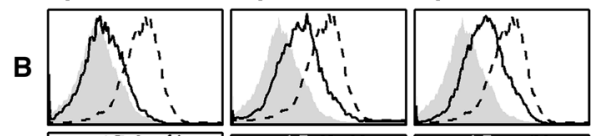

DC

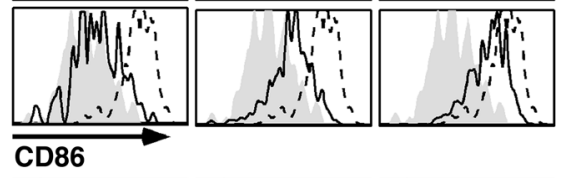

NK
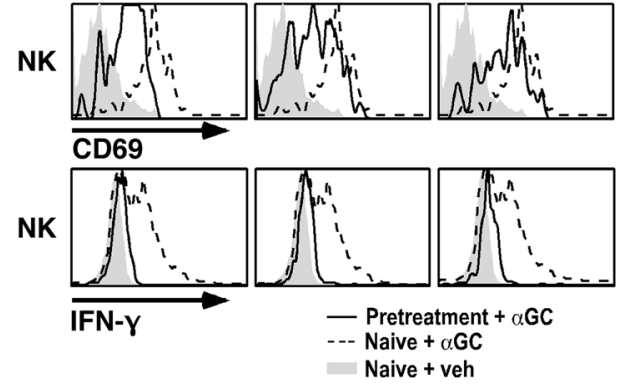


\section{Figure 5}

Bacteria can induce iNKT cell hyporesponsiveness to $\alpha$-GalCer rechallenge in vivo. (A, C, E, and $\mathbf{G}$ ) At the indicated times after injection with heat-killed $E$. coli $(\mathbf{A})$, live $L$. monocytogenes $(\mathbf{C})$, heat-killed $S$. aureus $(\mathbf{E})$, or heat-killed $S$. typhimurium $(\mathbf{G})$, mice were rechallenged in vivo with vehicle or $\alpha$-GalCer $(1 \mu \mathrm{g} /$ mouse, i.p.). Mice were sacrificed 3 days later, and spleen cells were stained with anti-TCR- $\beta$-FITC, anti-B220PerCP, and tetramer-allophycocyanin and analyzed by flow cytometry. Numbers indicate the percentage of TCR- $\beta^{+}$tetramer cells among B220cells. Data represent results obtained in at least 2 separate experiments involving 5-7 mice per group. (B, D, F, and $\mathbf{H}$ ) Total spleen iNKT cells calculated from the experiments shown in $\mathbf{A}, \mathbf{C}, \mathbf{E}$, and $\mathbf{G}$, respectively. ${ }^{*} P<0.05$ compared with naive mice rechallenged with $\alpha$-GalCer. (I) Hyporesponsive iNKT cells are defective in transactivating B cells, DCs, and NK cells in vivo. Mice were injected with the indicated bacteria and rechallenged with $\alpha$-GalCer $(1 \mu \mathrm{g} / \mathrm{mouse}$, i.p) 3 weeks later. Mice were then sacrificed at the 24-hour time point, and spleen mononuclear cells were stained with different combinations of anti-CD86-PE, anti-B220PerCP, anti-CD11c-allophycocyanin, anti-CD69-FITC, anti-NK1.1-allophycocyanin, and anti-TCR- $\beta-\mathrm{PE}$. For IFN- $\gamma$ staining on NK cells, mice were sacrificed 6 hours following $\alpha$-GalCer rechallenge, and spleen mononuclear cells were cultured 2 hours in the presence of GolgiPlug. Cells were then stained with anti-IFN- $\gamma-\mathrm{FITC}$, anti-NK1.1-allophycocyanin, and anti-TCR- $\beta-P E$. Data shown are representative of 6 mice per group from 2 separate experiments.

S. typhimurium or with live L. monocytogenes, and treated these animals at different time points thereafter with $\alpha$-GalCer to observe iNKT cell expansion in vivo. Consistent with prior results $(19,20)$, $\alpha$-GalCer injection $(1 \mu \mathrm{g} /$ mouse, i.p.) into naive mice induced dramatic iNKT cell expansion, whereas iNKT cells failed to expand in mice treated 3 weeks earlier with a single dose of $\alpha$-GalCer (Figure $5, \mathrm{~A}-\mathrm{H})$. In mice treated with each of the bacteria tested, $\alpha$-GalCer failed to induce substantial iNKT cell expansion. This inhibition of iNKT cell expansion persisted for at least 3 weeks for heat-killed S. aureus (Figure 5, E and F) and S. typhimurium (Figure 5, G and $\mathrm{H}$ ) and 4 weeks for heat-killed E. coli (Figure 5, A and B) and live L. monocytogenes (Figure 5, C and D). Additional data revealed that these iNKT cells were defective in inducing CD86 expression on $\mathrm{B}$ cells and DCs, as well as CD69 expression and IFN- $\gamma$ production by NK cells (Figure 5I). These findings indicate that bacteria can induce iNKT cell hyporesponsiveness in vivo.

To investigate whether heat killing of bacteria influences their capacity to induce iNKT cell hyporesponsiveness, we compared the impact of heat-killed versus live E. coli or L. monocytogenes on iNKT cell responses. Results showed that both heat-killed and live bacteria induced iNKT cell hyporesponsiveness (Supplemental Figure 4).

Role for TLR ligands and IL-12 in bacteria-induced iNKT cell byporesponsiveness. Bacteria that lack cognate iNKT cell antigens can activate iNKT cells in a manner that depends on the activation of DCs by TLR ligands $(23,25,26)$. We therefore investigated whether TLR ligands can induce iNKT cell hyporesponsiveness. Our results showed that LPS and flagellin from E. coli and Salmonella were able to induce hyporesponsiveness in iNKT cells (Figure 6, A-E). Because IL-12 has been implicated as a critical cytokine in the capacity of bacteria and bacterial products to activate $i \operatorname{NKT}$ cells $(23,25,26)$, and because both LPS and flagellin induce IL-12 production by APCs (28), we investigated the role of this cytokine in bacteriainduced iNKT cell hyporesponsiveness using IL-12-deficient mice. Consistent with previous studies indicating an important role for IL-12 in the reciprocal interactions of iNKT cells and DCs
(29), splenocytes from IL-12-deficient mice showed a suppressed response to $\alpha$-GalCer as compared with wild-type splenocytes, regardless of prior in vivo treatment. Results (Figure 6, F and G) showed that the capacity of heat-killed E. coli to induce iNKT cell hyporesponsiveness required IL-12 expression, whereas induction of iNKT cell anergy mediated by $\alpha$-GalCer was independent of IL-12 expression. Furthermore, we found an important role of IL-12 for iNKT cell hyporesponsiveness induced by LPS and flagellin (Supplemental Figure 5). These findings indicate a critical role of TLR ligands and IL-12 in the capacity of bacteria to induce iNKT cell hyporesponsiveness.

Bacteria-induced iNKT cell hyporesponsiveness is thymus independent. iNKT cell hyporesponsiveness induced by bacteria might involve central or peripheral tolerance mechanisms. We therefore tested whether iNKT cell hyporesponsiveness required an intact thymus. No differences were observed in the iNKT cell response of euthymic versus athymic animals pretreated with heat-killed E. coli, heat-killed S. aureus, or live L. monocytogenes (Figure 7). In addition, we observed a similar pattern of NK1.1 downregulation in bacteria-treated euthymic and athymic mice (Supplemental Figure 6). We therefore concluded that central tolerance mechanisms do not play a significant role in the induction of iNKT cell hyporesponsiveness by bacteria.

Bacteria-induced iNKT cell byporesponsiveness is predominantly cell autonomous. iNKT cell tolerance induced by bacteria might be intrinsic to these cells or mediated by extrinsic factors such as tolerogenic APCs. We tested this issue for mice treated with heat-killed E. coli. We cultured splenic DCs, purified from naive or E. coli-treated mice, with liver iNKT cells purified from naive or E. coli-treated animals, in the presence of $\alpha$-GalCer. Results showed that iNKT cells derived from naive mice proliferated and secreted cytokines at normal or slightly reduced levels in the presence of DCs derived from all mice (Figure 8A). In sharp contrast, liver iNKT cells from mice treated with heat-killed $E$. coli showed dampened proliferation and cytokine secretion in response to DCs from both naive and E. coli-treated animals. To confirm these findings, we labeled splenic iNKT cells enriched from naive or bacteria-treated animals with CFSE, cultured these cells in vitro with $\alpha$-GalCer-loaded, splenic DCs enriched from naive or bacteria-treated animals, and analyzed CFSE dilution among iNKT cells (Figure 8B). Results showed that iNKT cells enriched from naive animals exhibited substantial CFSE dilution, regardless of the source of DCs used for stimulation. Further, naive DCs were unable to rescue hypoproliferation of iNKT cells purified from $\alpha$-GalCer- or E. coli-treated mice. These findings suggested that DC alterations have only a minor impact on the development of iNKT cell unresponsiveness.

To confirm these findings, we enriched DCs from naive mice, loaded these cells ex vivo with $\alpha$-GalCer, and injected the cells into naive or bacteria-treated animals for evaluation of iNKT cell expansion in the spleen. Results showed that naive DCs loaded with $\alpha$-GalCer were unable to rescue the hyporesponsive phenotype of splenic iNKT cells from bacteria-treated animals (Figure 8C). These findings indicate that iNKT cell hyporesponsiveness induced by heat-killed E. coli and live L. monocytogenes is not due to alterations in DC function and is most likely intrinsic to these cells.

PMA plus ionomycin, or $\alpha$-GalCer and IL-2, can overcome bacteriainduced iNKT cell byporesponsiveness. Next, we tested whether a combination of PMA and ionomycin, which bypasses proximal TCR signaling events, can overcome the hyporesponsive phenotype of iNKT cells induced by bacteria. Results showed that this treatment 
A

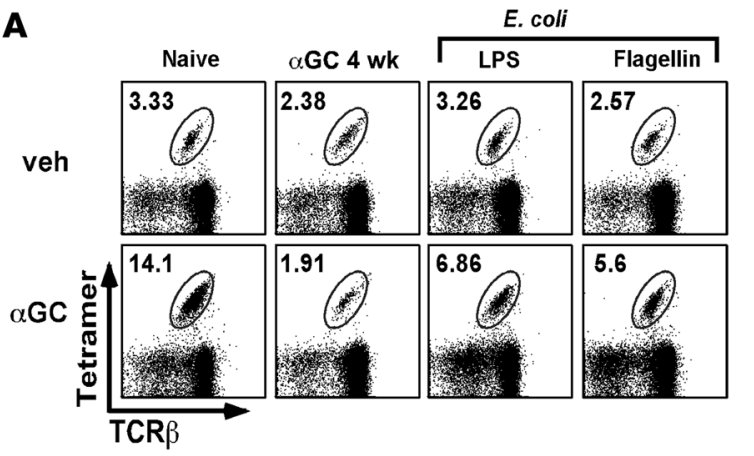

C

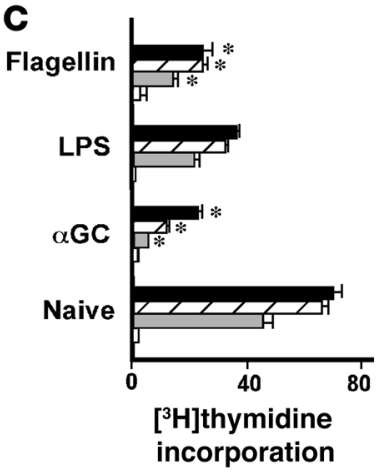

E

$\left(\mathrm{x} 10^{3} \mathrm{cpm}\right)$

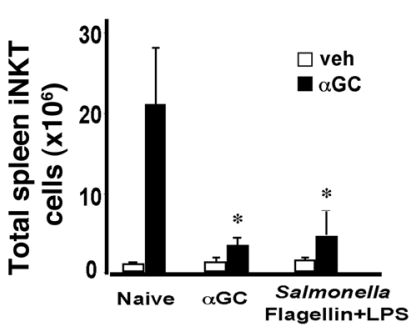

B

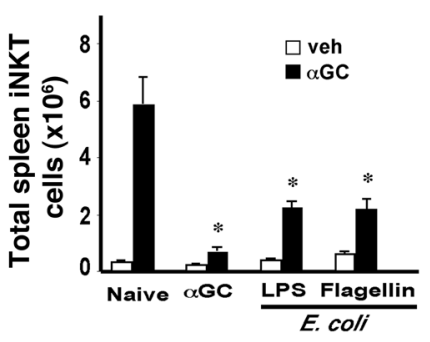

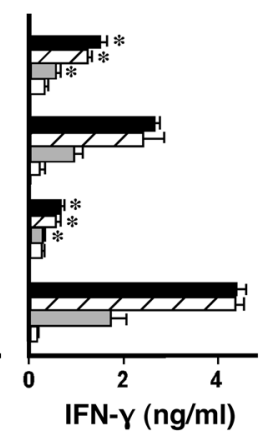

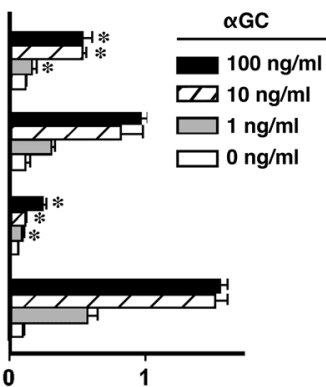

IL-4 (ng/ml)
D

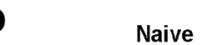

Naive $\quad$ GC 4 wk Falmonella veh
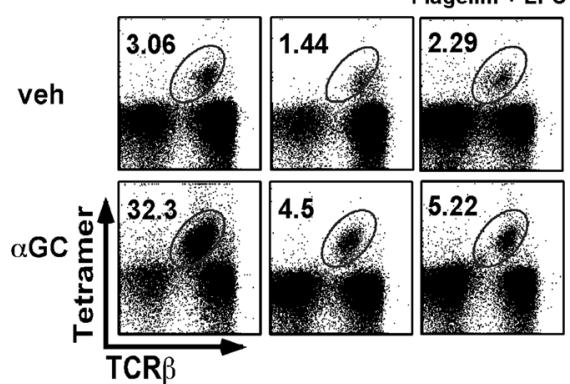

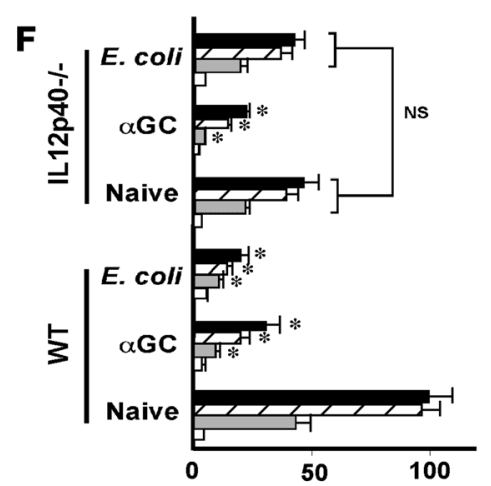

$\left[{ }^{3} \mathrm{H}\right]$ thymidine incorporation $(\% \mathrm{cpm})$
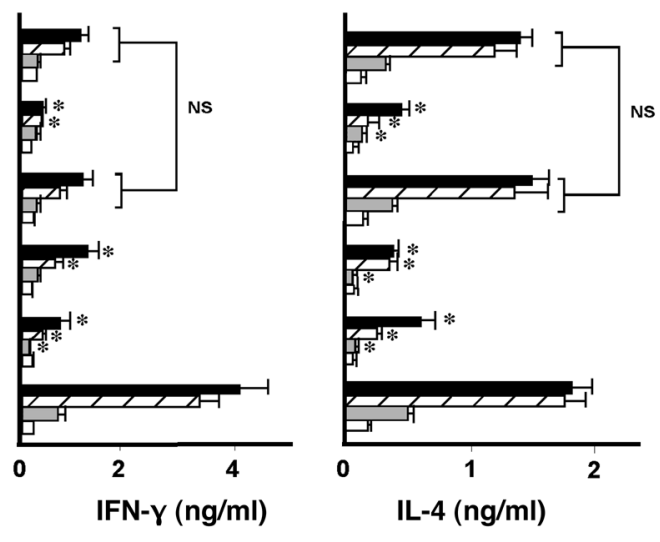

G WT IL12p40-I-

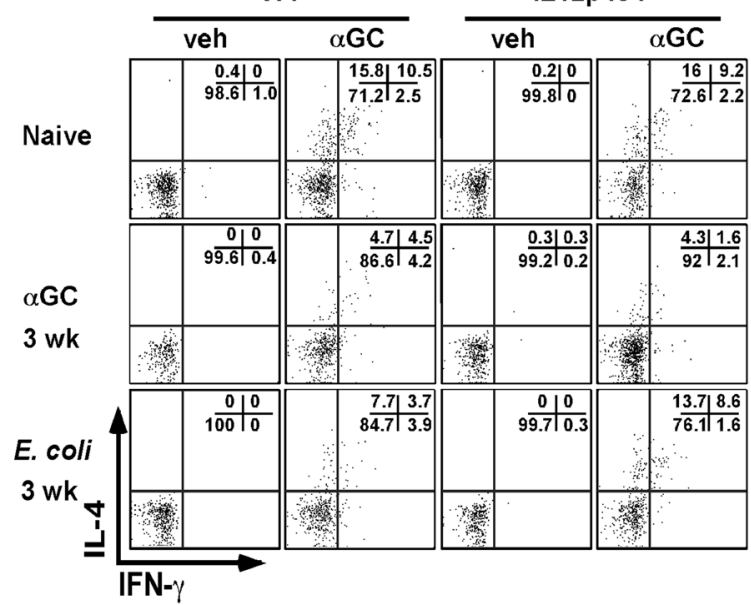

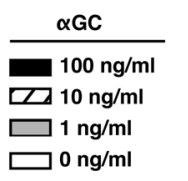




\section{Figure 6}

Role of bacterial TLR ligands and IL-12 in the induction of INKT cell hyporesponsiveness. (A) Mice were injected with E. coli flagellin (20 $\mu \mathrm{g}$ ) or LPS (3 doses of $10 \mu \mathrm{g}$ every 3 days) and 3 weeks later rechallenged in vivo with vehicle (veh) or $\alpha$-GalCer $(1 \mu \mathrm{g} / \mathrm{mouse}$, i.p.). Mice were sacrificed 3 days later, and spleen cells were stained. (B) Total spleen iNKT cells calculated from the experiments shown in $\mathbf{A}$. (C) In vitro response of splenocytes to $\alpha$-GalCer from mice treated 3 weeks earlier with $\alpha$-GalCer, $E$. coli flagellin, or $E$. coli LPS. Mice were injected with $\alpha$-GalCer or the indicated TLR ligands and sacrificed 3 weeks later, and splenocytes $\left(2 \times 10^{5}\right.$ per well) were cultured with graded doses of $\alpha$-GalCer. After 3 days, proliferation was assessed, and culture supernatants were evaluated for IL-4 and IFN- $\gamma$. (D) Mice were injected with Salmonella flagellin and LPS ( 3 doses of $10 \mu \mathrm{g}$ every 3 days) and 3 weeks later rechallenged in vivo with vehicle or $\alpha$-GalCer $(1 \mu \mathrm{g} /$ mouse, i.p.). Mice were sacrificed 3 days later, and spleen cells were stained. (E) Total spleen iNKT cells calculated from the experiments shown in $\mathbf{D}$. (F and $\mathbf{G})$ E. coli-induced iNKT cell hyporesponsiveness is dependent on IL-12. (F) Wild-type and IL-12p40-deficient mice were treated with $\alpha-G a l C e r$ or heat-killed $E$. coli. Three weeks later, mice were sacrificed and splenocytes cultured with graded doses of $\alpha$-GalCer; proliferation was assessed, and culture supernatants were evaluated for IL-4 and IFN- $\gamma$. (G) Spleen cells were prepared at the indicated time points and cultured for 6 hours with vehicle or $100 \mathrm{ng} / \mathrm{ml}$ $\alpha$-GalCer in the presence of GolgiPlug. Cells were then harvested and stained. Data in $\mathbf{B}, \mathbf{C}, \mathbf{E}$, and $\mathbf{F}$ are presented as mean \pm SEM. ${ }^{*} P<0.05$ compared with naive mice.

was able to overcome iNKT cell hyporesponsiveness induced by heat-killed E. coli and live L. monocytogenes (Figure 9A). However, in most experiments, rescue of iNKT cell function in bacteria-treated animals was not as complete as that in $\alpha$-GalCer-treated animals.

We also investigated whether IL-2, which can overcome the proliferative defect of iNKT cells rendered anergic in response to $\alpha$ GalCer treatment $(19,20)$, can rescue iNKT cell proliferation in mice treated 3 weeks earlier with heat-killed E. coli. We found that IL-2 was able to restore the proliferative function of hyporesponsive iNKT cells (Figure 9B), suggesting similarities between $\alpha$-GalCer- and bacteria-induced iNKT cell hyporesponsiveness.

Impact of bacteria-induced iNKT cell byporesponsiveness on ConAinduced hepatitis. To determine whether bacteria can influence iNKT cell-mediated effector functions in a disease setting, we evaluated iNKT cell function in a model of hepatitis induced by concanavalin A (ConA). ConA-induced hepatitis is a well-characterized mouse model for human autoimmune hepatitis that is dependent on iNKT cell function (30). Consistent with prior studies (30), CD1d-deficient mice, compared with wild-type mice, showed significantly reduced liver damage following ConA injection (Figure 10A). Likewise, mice treated with heat-killed E. coli or $S$. aureus or with live L. monocytogenes, as compared with naive mice, experienced significantly less liver damage, as assessed by serum alanine aminotransferase (ALT) levels (Figure 10, B and C). Interestingly, bacteria conferred better protection from ConA-induced liver injury than $\alpha$-GalCer (Figure 10C).

Impact of E. coli-induced iNKT cell byporesponsiveness on the therapentic activities of $\alpha$-GalCer. The immunomodulatory properties of iNKT cells have been exploited for the development of immunotherapies for cancer and for preventing autoimmunity (1-3). We therefore tested whether exposure to bacteria can influence the therapeutic activities of $\alpha$-GalCer, using a model for lung metastasis induced by B16 melanoma cells and the EAE model of multiple sclerosis. Mice were treated with heat-killed E. coli or live L. monocytogenes, and 3 weeks later these animals were injected with B16 cells for induction of tumor metastases or treated with $\mathrm{MOG}_{35-55}$ peptide in CFA for induction of EAE. Mice were then treated with a series of vehicle or $\alpha$-GalCer injections. Results showed that, even in the absence of $\alpha$-GalCer treatment, tumor burden in E. coli-treated animals, but not L. monocytogenes-treated animals, was substantially lower when compared with the tumor burden in naive animals (Figure 11A). This may be due to primed innate immune responses in E. coli-treated animals. However, $\alpha$-GalCer was unable to enhance the clearance of B16 tumors from E. coli-treated mice and instead slightly enhanced tumor burden in these animals (although differences were not statistically significant). Likewise, $\alpha$-GalCer was unable to promote tumor clearance in mice treated with $L$. monocytogenes. In contrast, however, iNKT cells in E. coli-treated animals retained their capacity to prevent the development of EAE (Figure 11B).

\section{Discussion}

Immune responses mediated by peptide-reactive, MHC-restricted $\mathrm{T}$ cells are characterized by a period of $\mathrm{T}$ cell activation, followed by proliferation and differentiation, elaboration of effector functions, a decline phase in which the pool of antigen-specific T cells contracts, and the development of immunological memory. In sharp contrast, little is known regarding the immune response mediated by glycolipid-reactive, CD1d-restricted iNKT cells. We and others have shown that treatment of mice with the potent iNKT cell agonist $\alpha$-GalCer results in the rapid activation and proliferation of these cells, followed by homeostatic contraction of the iNKT cell population and acquisition of an anergic phenotype (15). Here we have demonstrated that iNKT cells activated in response to multiple bacterial microorganisms acquire a similar hyporesponsive phenotype, which can significantly impact subsequent iNKT cell-mediated immune responses and the efficacy of iNKT cell-based immunotherapy.

We tested the impact of bacteria on the phenotype and functional responses of iNKT cells. While each of the bacteria tested, as evidenced by CD69 induction and NK1.1 downregulation (Figure 1A and data not shown), was able to activate iNKT cells, we observed long-term effects on iNKT cell function for E. coli, S. aureus, S. typhimurium, and L. monocytogenes (Figure 2) but not S. capsulata (Figure 2), Enterococcus faecalis (data not shown), and Streptococcus pyogenes (data not shown). Whether bacteria were heat killed or live did not impact the outcome on iNKT cell responses (Supplemental Figure 4). The divergent effects of distinct bacteria on iNKT cell function may be due, in part, to differences in the mechanisms by which iNKT cells become activated. Although the precise mechanisms by which iNKT cells become activated in response to bacteria remain incompletely understood, 2 general mechanisms have been proposed $(23,26)$. Some bacteria, such as Sphingomonas and Borrelia species, contain glycolipids in their cell walls that can bind CD1d and directly activate iNKT cells. In this context, it was surprising that live $S$. capsulata, despite its capacity to activate iNKT cells, failed to induce iNKT cell hyporesponsiveness, even when used at a sublethal dose. Bacteria that lack cognate iNKT cell antigens can activate iNKT cells by stimulating the production of proinflammatory cytokines by activating TLRs on APCs $(23,25)$. In this regard, we found that the TLR4 agonist LPS and the TLR5 agonist flagellin (Figure 6, A-E), but not the TLR9 agonist CPG, the TLR7 agonist imiquimod, the TLR2 agonist lipoteichoic acid, or the TLR3 agonist polyinosinic acid-polycyti- 


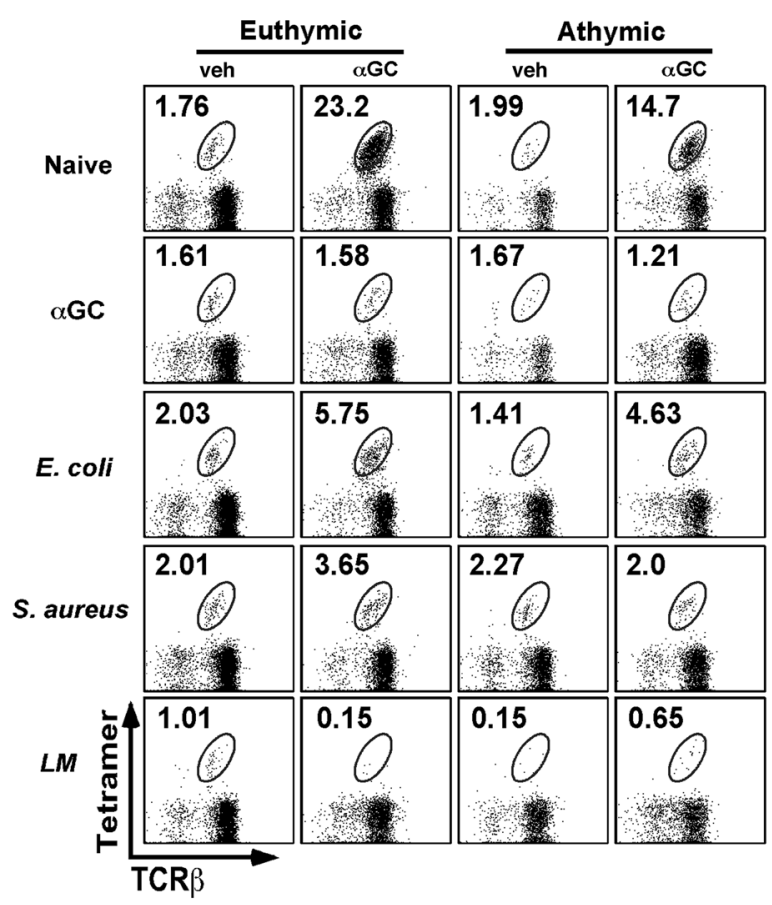

dylic acid (data not shown), induced iNKT cell hyporesponsiveness. Prior studies have indicated a key role of IL-12 for activation of iNKT cells by bacteria and bacterial LPS $(10,23,25,31)$. We confirmed that IL-12 plays an important role in activating iNKT cells in response to heat-killed E. coli (data not shown), and studies with IL-12-deficient mice revealed a critical role of this cytokine for inducing iNKT cell hyporesponsiveness to heat-killed E. coli (Figure 6, F and G), LPS, and flagellin (Supplemental Figure 5). Each of the bacterial organisms investigated in this study likely has multiple mechanisms to induce the production of proinflammatory cytokines by APCs and, thus, to activate iNKT cells. Induction of iNKT cell hyporesponsiveness therefore might be influenced by a variety of factors, including the mechanism and extent of iNKT cell activation. In this regard, we noticed that the capacity of bacteria to induce iNKT cell hyporesponsiveness correlated with sustained NK1.1 downregulation in the spleen (Figure 1B) and with transient iNKT cell depletion in the liver (Figure 1B), both of which are also observed after $\alpha$-GalCer treatment $(19,20)$. In the case of $L$. monocytogenes, we also observed transient iNKT cell depletion in the spleen (Figure 4, A and B), which likely reflects strong iNKT cell activation. A similar but more sustained depletion of iNKT cells has been observed in mice following acute infection with lymphocytic choriomeningitis virus (LCMV) (32).

iNKT cell hyporesponsiveness induced by bacteria exhibited a number of similarities to iNKT cell anergy induced by $\alpha$-GalCer (15). First, as already discussed, iNKT cell hyporesponsiveness correlated with sustained NK1.1 downregulation by splenic iNKT cells (Figure 1B), and we observed a similar downregulation of the activating NK cell receptor NKG2D and the CD94 subunit of the NKG2/CD94 family of NK cell receptors (Supplemental Figure 3). These alterations in NK cell receptor expression might contribute to the hyporesponsive phenotype of iNKT cells. Second, iNKT cell hyporesponsiveness correlated with a transient decrease in liver iNKT cell numbers (Figure 1B, Figure 3, A and B, and Figure 4, A and $\mathrm{B})$. Third, iNKT cell hyporesponsiveness was maintained for at

\section{Figure 7}

Bacteria-induced iNKT cell hyporesponsiveness is thymus independent. Thymectomized and nonthymectomized B6 mice were treated with $\alpha$-GalCer $(5 \mu \mathrm{g} / \mathrm{mouse}$, i.p) or the indicated bacteria. Three weeks later, mice were rechallenged with vehicle or $\alpha$-GalCer $(1 \mu \mathrm{g} /$ mouse, i.p) in vivo. Mice were sacrificed at day 3 , and spleen cells were stained with anti-TCR- $\beta$-FITC, anti-B220-PerCP, and tetramer-allophycocyanin and analyzed by flow cytometry. Data shown are representative of 2 mice per group.

least 4 weeks (Figure 2, Figure 3C, and Figure 4C). Fourth, iNKT cell hyporesponsiveness was induced independent of a functional thymus (Figure 7), implying peripheral rather than central tolerance mechanisms. Fifth, hyporesponsiveness was predominantly iNKT cell autonomous (Figure 8). Finally, iNKT cell hyporesponsiveness could be overcome by treatment of these cells with reagents (i.e., PMA plus ionomycin) that can bypass early TCR signaling events, and the proliferative capacity of these cells could be rescued by treatment with $\alpha$-GalCer in the presence of IL-2 (Figure 9). These similarities between bacteria- and $\alpha$-GalCer-induced iNKT cell hyporesponsiveness suggest similar mechanisms. Nevertheless, one striking difference in the capacity of bacteria and $\alpha$-GalCer to induce iNKT cell hyporesponsiveness is the requirement for IL-12 expression, which is critical for bacteria- but not for $\alpha$-GalCerinduced iNKT cell hyporesponsiveness (Figure 6, F and G).

A recent study has shown that sulfatide, a ligand for a subset of CD1d-restricted NKT cells expressing diverse TCRs, can also induce hyporesponsiveness in iNKT cells (33). Unlike the anergy induced by $\alpha$-GalCer, but similar to bacteria-induced hyporesponsiveness, anergy induced in iNKT cells by sulfatide required IL-12 expression. These findings suggest that multiple stimuli and pathways can result in iNKT cell hyporesponsiveness with overlapping but distinct mechanisms of induction and, possibly, maintenance.

iNKT cell activation can have a number of detrimental effects in mice, including the induction of liver injury (34), abortions (35), and exacerbation of atherosclerosis (36) and allergic reactions (37). Thus, it is likely that bacteria-induced iNKT cell hyporesponsiveness serves to avoid such deleterious outcomes of iNKT cell activation. In addition to inducing iNKT cell hyporesponsiveness, some pathogens, such as L. monocytogenes (the present study) and LCMV (32), induce substantial iNKT cell apoptosis, which likely represents an additional mechanism to avoid the deleterious effects of sustained iNKT cell activation. Our finding that treatment of mice with E. coli, S. aureus, or L. monocytogenes suppressed ConA-induced hepatitis (Figure 10) supports this notion.

In humans, it has been well documented that iNKT cell numbers and functions differ widely among individuals $(38,39)$. Our finding that many bacteria can induce iNKT cell hyporesponsiveness, together with the observation that certain pathogens can induce short-term (e.g., L. monocytogenes; this study) or long-term (e.g., LCMV; ref. 32) depletion of the iNKT cell population, provides a potential explanation for this observation. A role for microbial pathogens in the variability of human iNKT cell numbers and functions is also consistent with the finding that iNKT cell numbers in humans are suppressed during certain chronic infections, including interactions with HIV (38) and Mycobacterium tuberculosis (40).

iNKT cells are promising targets for immunotherapy of a variety of diseases, including cancer and autoimmunity $(1-3,41)$. Our studies revealed that bacteria-induced iNKT cell hyporesponsiveness impacts the efficacy of iNKT cell-based immunotherapies. We 
A DC NKT

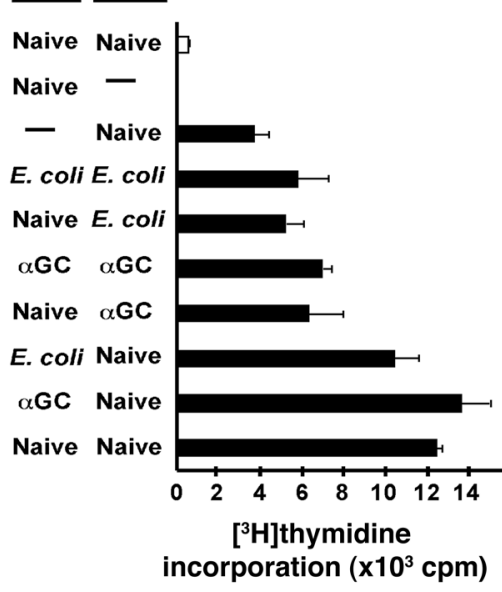

B

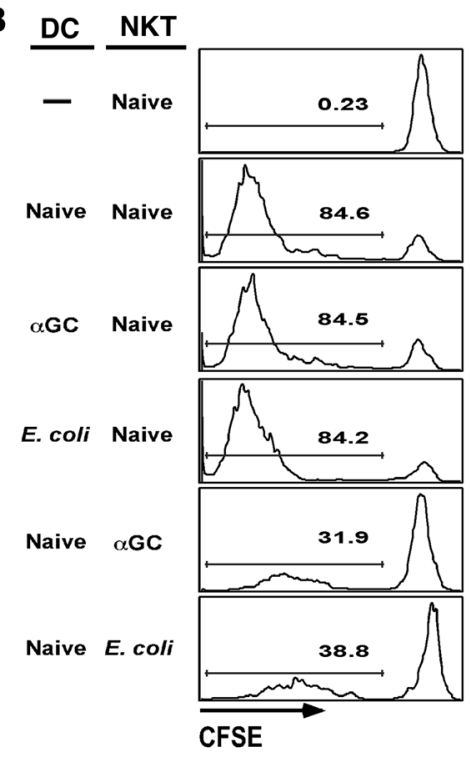

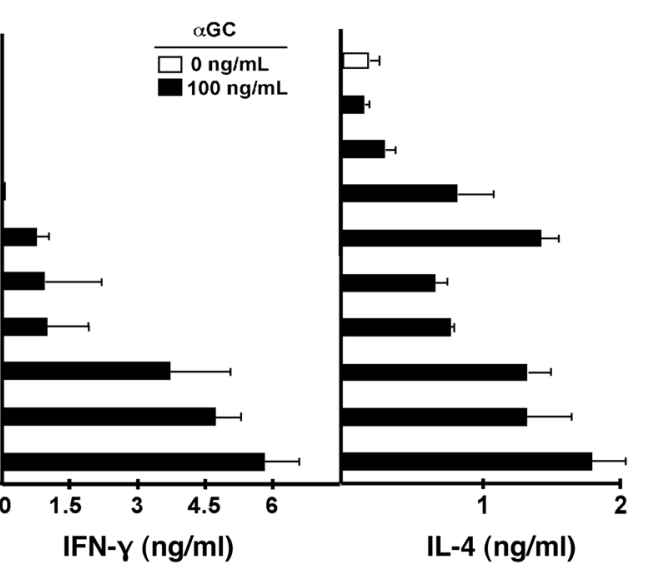

C E.coli

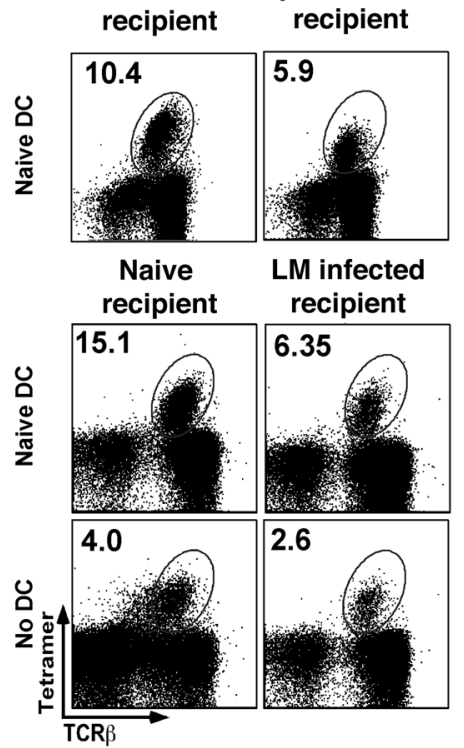

Figure 8

Bacteria-induced iNKT cell hyporesponsiveness is predominantly iNKT cell autonomous. (A) Mice were injected with $\alpha$-GalCer or heat-killed $E$. coli and sacrificed at 3 weeks. DCs from the spleen and iNKT cells from the liver were then enriched as described in Methods. iNKT cells $\left(1 \times 10^{5}\right.$ per well) and DCs $\left(5 \times 10^{4}\right.$ per well) were then cultured in different combinations in the presence or absence of $\alpha$-GalCer. Proliferation was assessed by $\left[{ }^{3} \mathrm{H}\right]$ thymidine incorporation, and IFN- $\gamma$ and IL-4 levels in the supernatant were evaluated by ELISA. Data shown are the mean \pm SD of 2 wells per group and representative of 2 independent experiments. (B) Mice were injected with $\alpha$-GalCer or heat-killed E. coli and sacrificed at 3 weeks. DCs and iNKT cells were then MACS purified as described in Methods. DCs $\left(2 \times 10^{4}\right.$ per well $)$ were loaded with $\alpha$-GalCer and cultured with splenic CFSE-labeled iNKT cells $\left(1 \times 10^{5}\right.$ per well). Cells were harvested 3 days later, stained with anti-B220-PerCP, tetramer-allophycocyanin, and analyzed by flow cytometry. Data shown are CFSE staining on iNKT cells. Three mice per group were pooled for the experiment. (C) Mice were left untreated or injected with heat-killed $E$. coli or live L. monocytogenes. DCs were MACS purified from naive mice, pulsed with $\alpha$-GalCer, washed, and then injected i.v. $\left(2 \times 10^{5} \mathrm{DCs}\right.$ per mouse) into naive mice or mice treated 3 weeks earlier with the indicated bacteria. As a control, mice were also treated without DCs. Mice were sacrificed 3 days later, and splenocytes were stained with anti-TCR- $\beta-F I T C$, anti-B220-PerCP, and tetramer-allophycocyanin and analyzed by flow cytometry. Data shown are representative of 2 mice per group. demonstrated that heat-killed E. coli and live L. monocytogenes abrogated the capacity of $\alpha$-GalCer to protect mice against the development of B16 tumors, but we did not observe any effects of E. coli on the capacity of $\alpha$-GalCer to protect mice against the induction of EAE (Figure 11). These effects of bacteria on the therapeutic activities of $\alpha$-GalCer are very similar to those mediated by $\alpha$-GalCerinduced iNKT cell anergy (19). Although the precise mechanisms remain unclear, IFN- $\gamma$ and iNKT cell-mediated transactivation of DCs and NK cells likely play important roles in the therapeutic effects of $\alpha$-GalCer against B16 tumor cells (42), whereas IL-4, IL-10, and IFN- $\gamma$ all have been implicated in the therapeutic efficacy of $\alpha$-GalCer against EAE (43-45). Our finding that $\alpha$-GalCer-activated, hyporesponsive iNKT cells are defective in transactivating DCs and NK cells (Figure 5I) provides a potential explanation for loss of the beneficial effect of iNKT cells against B16 metastases. In the case of EAE, it is possible that the levels of cytokines produced by hyporesponsive iNKT cells are sufficient to promote the tolerogenic activities of these cells and prevent EAE disease. Indeed, we found that DCs from mice treated with $\alpha$-GalCer 3 weeks after challenge with $\alpha$-GalCer or heat-killed E. coli exhibited a profound increase in IL-10 secretion in response to in vitro stimulation with LPS or CpG (Supplemental Figure 7). In conclusion, our findings argue in favor of the hypothesis that infections and vaccination might limit the utility of $\alpha$-GalCer therapy.

\section{Methods}

Mice. Female C57BL/6 (B6) mice, thymectomized adult B6 mice, and IL-12p40-deficient mice were purchased from The Jackson Laboratory. All animal studies were approved by the Institutional Animal Care and Use Committee of Vanderbilt University.

Reagents. $\alpha$-GalCer (KRN7000) was kindly provided by the Kirin Brewery Co. and was reconstituted in PBS containing $0.5 \%$ polysorbate-20 (SigmaAldrich). CD1d monomers were obtained from the NIH. Fluorescently labeled tetrameric CD1d molecules loaded with $\alpha$-GalCer (CD1d tetramers) were prepared as described previously (46). Anti-TCR- $\beta$-FITC and -allophycocyanin, anti-NK1.1-PE and -allophycocyanin, anti-B220-peridinin chlorophyll protein (anti-B220-PerCP), anti-CD3-PerCP, anti-CD80-PE, anti-CD86-PE, anti-IL-4-allophycocyanin, anti-IFN- $\gamma$-FITC, anti-CD69- 
A

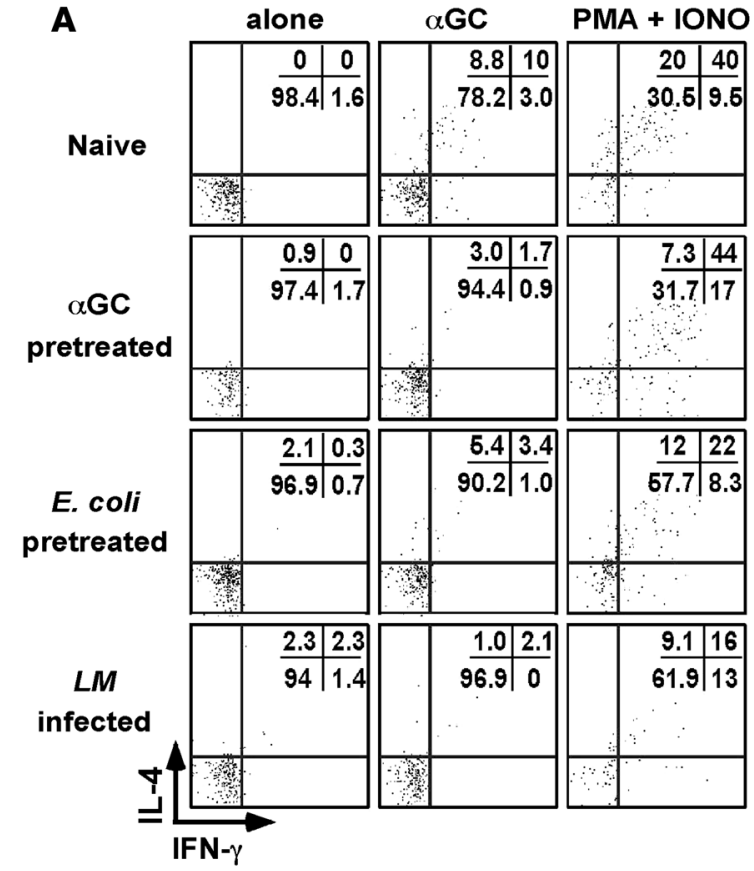

B

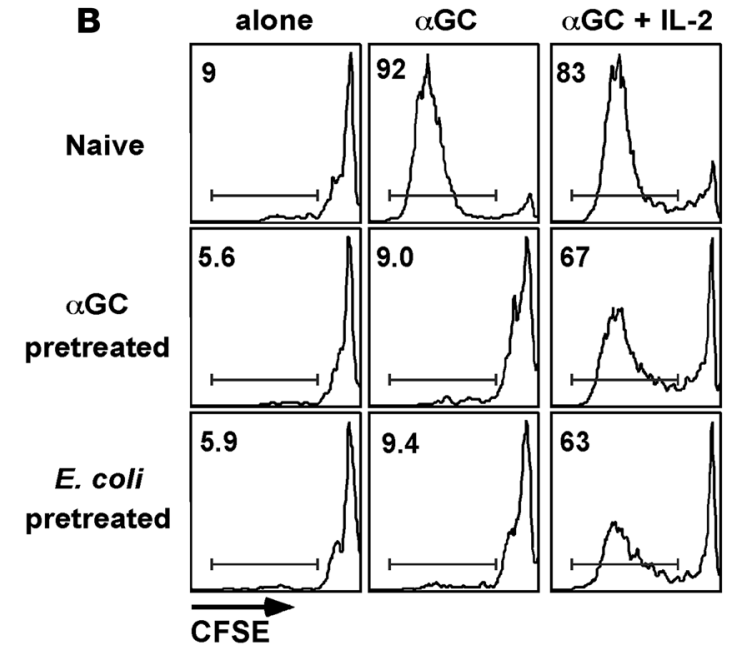

Figure 9

Bacteria-induced iNKT cell hyporesponsiveness can be overcome by treatment with PMA plus ionomycin or with $\alpha$-GalCer plus IL-2. (A) Spleen cells were prepared from mice treated 4 weeks earlier with $\alpha$-GalCer or the indicated bacteria, cultured in vitro $\left(2 \times 10^{5}\right.$ per well) for 6 hours in plain medium (alone), $100 \mathrm{ng} / \mathrm{ml} \alpha$-GalCer, or a combination of $10 \mathrm{ng} / \mathrm{ml}$ PMA and $1 \mu \mathrm{M}$ ionomycin (PMA + IONO), in the presence of GolgiPlug to allow intracellular accumulation of cytokines. Cells were then harvested and surface stained with tetramer-PE and anti-B220-PerCP, followed by intracellular staining with anti-IFN- $\gamma-$ FITC and anti-IL-4-allophycocyanin. Data are shown for B220-tetramer+ cells. Numbers indicate the percentage of cells within each quadrant. Data shown are representative of 3 independent experiments with 2 mice in each group per experiment. (B) IL-2 overcomes the proliferative defect of hyporesponsive iNKT cells in vitro. Spleen cells from naive mice or from mice injected 1 month earlier with $\alpha$-GalCer or heat-killed $E$. coli were labeled with CFSE. Cells $\left(2 \times 10^{5}\right.$ per well) were then cultured with $\alpha$-GalCer $(100 \mathrm{ng} / \mathrm{ml})$ for 24 hours in the presence or absence of IL-2 $(10 \mathrm{ng} / \mathrm{ml})$. Cells were then washed and cultured for an additional $96 \mathrm{hours}$ without $\alpha$-GalCer in the presence or absence IL-2. At the end of the culture period, cells were harvested, stained with tetramer-allophycocyanin and anti-B220-PerCP, and analyzed by flow cytometry. CFSE dilution was analyzed on B220-tetramer ${ }^{+}$cells. Representative data from 2 independent experiments are shown.

FITC, anti-CD11c-allophycocyanin, and streptavidin-PE-cyanide dye 5 were obtained from BD Biosciences - Pharmingen. Mouse recombinant IL-2 was also obtained from BD Biosciences - Pharmingen; PMA and ionomycin from MP Biomedicals; complete and incomplete Freund's adjuvant from BD Biosciences - Pharmingen; CFSE from Invitrogen; ConA from MP Biomedicals; lipoteichoic acid, E. coli, and Salmonella LPS from Sigma-Aldrich; $\mathrm{CPG}$, imiquimod, and Salmonella flagellin from Invivogen; and polyinosinic acid-polycytidylic acid from Amersham Pharmacia. E. coli flagellin was purified from cultures as described previously (47).

Treatment of mice with heat-killed or live bacteria. E. faecalis (catalog no. 29212; ATCC), E. coli (catalog no. 25922; ATCC), S. aureus (catalog no. 25923; ATCC), and S. pyogenes (catalog no.19615; ATCC) were obtained from Yi-Wei Tang (Vanderbilt Medical Center); S. typhimurium ( $\chi 4550)$ was obtained from Roy Curtiss (Arizona State University, Tempe, Arizona, USA); and L. monocytogenes was obtained from Hao Shen (University of Pennsylvania School of Medicine, Philadelphia, Pennsylvania, USA). Each of these organisms was grown on Brain Heart Infusion Agar (Difco; BD Diagnostics) plates, and individual colonies were cultured overnight in Brain Heart Infusion Broth, diluted in fresh broth, and grown for 8 hours at $37^{\circ} \mathrm{C}$ to stationary phase, washed, and resuspended in PBS. S. capsulata (catalog no. 14666; ATCC) was obtained from ATCC and grown in Mueller-Hinton broth, washed, and diluted in PBS buffer. Heat-killed bacteria were prepared by 2-hour exposure to $75^{\circ} \mathrm{C}$, except for S. typhimurium, which was incubated in boiling water for 45 minutes. Heat-killed bacteria were subsequently stored at $-80^{\circ} \mathrm{C}$. Heat-killed bacteria $\left(0.75 \times 10^{9}\right.$ to $1 \times 10^{9} \mathrm{CFU}$ in $\left.200 \mu \mathrm{lPBS}\right)$ were injected i.v. into mice. Live bacteria were administered i.v. in $200 \mu \mathrm{l} \mathrm{PBS}$, at a dose of $5 \times 10^{4} \mathrm{CFU}$ for L. monocytogenes, $1 \times 10^{8}$ to $2 \times 10^{8} \mathrm{CFU}$ for S. capsulata, or $5 \times 10^{5} \mathrm{CFU}$ for $E$. coli. Mice were sacrificed and analyzed at various time points after injection.

Flow cytometry. Single-cell suspensions of the spleen and liver were prepared and stained with fluorescently labeled $\mathrm{mAbs}$ as described previously (48). In all experiments, dead cells were excluded from the analysis by electronic gating. The iNKT cell population was identified as B220-TCR- $\beta^{+}$ tetramer ${ }^{+}$cells. For intracellular cytokine staining, cells were treated with GolgiPlug (BD Biosciences - Pharmingen) and permeabilized with Cytofix/ Cytoperm reagents (BD Biosciences - Pharmingen) according to the manufacturer's protocol. For staining of DCs, Fc receptors were first blocked by addition of anti-CD16/32 antibodies (BD Biosciences - Pharmingen), and DCs were identified on the basis of high CD11c expression. Flow cytometry was performed using a FACSCalibur instrument with CellQuest software (BD Biosciences - Immunocytometry Systems), and the acquired data were analyzed using FlowJo software (Tree Star Inc.)

Measurement of in vivo and in vitro responses to $\alpha$-GalCer. For evaluation of in vivo iNKT cell responses to $\alpha$-GalCer, mice were injected i.p. with $1 \mu \mathrm{g}$ $\alpha$-GalCer in $200 \mu \mathrm{l}$ PBS containing $0.025 \%$ polysorbate- 20 (vehicle). At different time points, splenocytes and liver mononuclear cells were stained 
A
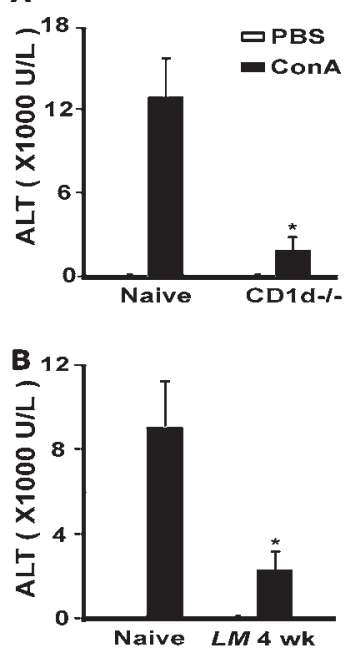

$\operatorname{Exp} 1$

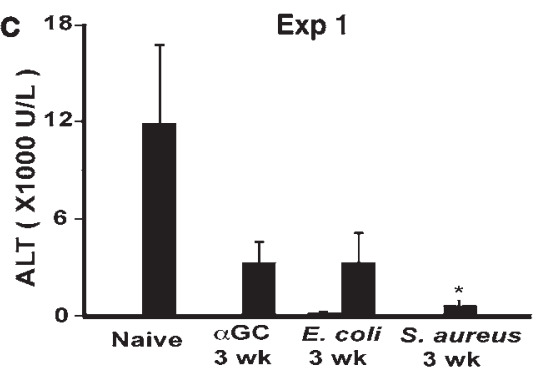

Exp 2

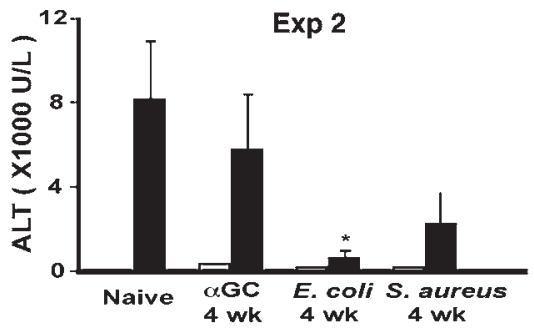

\section{Figure 10}

Impact of bacteria-induced iNKT cell hyporesponsiveness on ConA-induced hepatitis. Wild-type or CD1d-deficient (A) mice were injected with $\alpha$-GalCer, live L. monocytogenes (B), or heat-killed E. coli or S. aureus (C), and, 3-4 weeks later, mice were challenged with PBS or ConA ( $350 \mu \mathrm{g} /$ mouse in PBS). Mice were bled 24 hours later, and serum ALT levels were measured. Results represent the mean \pm SEM of 8 mice per group in ConA-treated groups or 2 mice per group in PBS-treated groups. ${ }^{*} P<0.05$ compared with naive mice treated with ConA. with fluorescently labeled mAbs and analyzed by flow cytometry. For evaluation of in vitro iNKT cell responses, splenocytes were plated in U-bottomed 96-well plates at $2 \times 10^{5}$ cells per well in RPMI medium containing $10 \%$ FCS (R-10) in the presence of titrated doses of $\alpha$-GalCer or vehicle. For proliferation assays, $1 \mu \mathrm{Ci}$ of $\left[{ }^{3} \mathrm{H}\right]$ thymidine (MP Biomedicals) was added to the wells after 60 hours of culture, and cells were cultured for an additional 12 hours. Cells were then harvested, and uptake of radioactivity was measured in a beta counter. For measurement of cytokine secretion in vitro, supernatants were harvested after 60 hours of culture, and cytokine levels were measured by ELISA.

ELISA. A standard sandwich ELISA was performed to measure mouse IFN- $\gamma$, IL-4, IL-10, IL-12, and IL-2. IFN- $\gamma$ - and IL-4-paired antibodies were obtained from R\&D Systems, and IL-10, IL-12, and IL-2-paired antibodies were obtained from BD Biosciences - Pharmingen. Cytokine standards were obtained from BD Biosciences - Pharmingen. For detection, streptavidin-HRP conjugate (Zymed; Invitrogen) was used, and the color was developed with the substrate 3,3',5,5'-tetramethylbenzidine (Dako) in the presence of $\mathrm{H}_{2} \mathrm{O}_{2}$.

Isolation of splenic DCs. Spleens were cut into small pieces and digested with $0.2 \mathrm{mg} / \mathrm{ml}$ collagenase D (Roche Diagnostics) in FCS-free RPMI

\section{Figure 11}

Impact of $E$. coli-induced iNKT cell hyporesponsiveness on the therapeutic activities of $\alpha$-GalCer. (A) Determination of B16 tumor lung metastasis formation. B6 mice were left untreated or injected with bacteria, and, 4 weeks later, mice were challenged i.v. with $3 \times 10^{5}$ syngeneic B16 melanoma cells and treated with $\alpha$-GalCer $(5 \mu \mathrm{g} / \mathrm{injec}-$ tion) or vehicle at 0,4 , and 8 days after tumor challenge. Mice were sacrificed after 15 days, and the number of metastatic nodules in the lungs counted. Results shown are the mean \pm SEM of 2 experiments with 4 mice in each group per experiment. (B) Determination of EAE. B6 mice were treated with heat-killed $E$. coli, and, 3 weeks later, mice were immunized with $\mathrm{MOG}_{35-55}$ peptide for induction of $\mathrm{EAE}$, treated with $\alpha$-GalCer ( $5 \mu \mathrm{g} /$ injection) or vehicle on days 0,4 , and 7 , and followed for clinical signs of EAE. Results shown are 1 representative experiment of 2 with 5-6 mice in each group. medium for 45 minutes. The digestion was terminated by addition of cold R-10 medium. Red blood cells were lysed using ACK lysing buffer (Lonza). DCs were enriched based on expression of the CD11c marker by magnetic sorting using MACS beads (Miltenyi Biotec) according to the manufacturer's protocol. The purity of enriched cell populations was $80 \%-85 \%$ for DCs (data not shown). Purified DCs were pulsed for 3 hours with $200 \mathrm{ng} / \mathrm{ml} \alpha$-GalCer at $37^{\circ} \mathrm{C}$. Cells were then washed 3 times in R-10 medium to remove excess $\alpha$-GalCer and injected i.v. into B6 mice $\left(2 \times 10^{5} \mathrm{DCs}\right.$ per mouse). Mice were sacrificed 3 days later for analysis of iNKT cell function.

Enrichment of iNKT cells. For enrichment of liver iNKT cells, livers were perfused with cold PBS and then pressed through a $70-\mu \mathrm{m}$ cell strainer. Cells were suspended in $40 \mathrm{ml}$ RPMI medium in a $50-\mathrm{ml}$ conical tube and allowed to stand on ice for 45 minutes. The supernatant was then centrifuged, resuspended in cold $40 \%$ Percoll (GE Healthcare), and underlaid with $60 \%$ Percoll. Cells were centrifuged at $1,500 \mathrm{~g}$ for 20 minutes at $4^{\circ} \mathrm{C}$. Mononuclear cells at the interphase of the $40 \%$ and $60 \%$ Percoll solutions were collected and washed twice with R-10 medium. Two rounds of panning, 2 hours each, were then carried out to remove plastic-adherent APCs. The frequency of liver iNKT cells was then analyzed by flow cytometry in
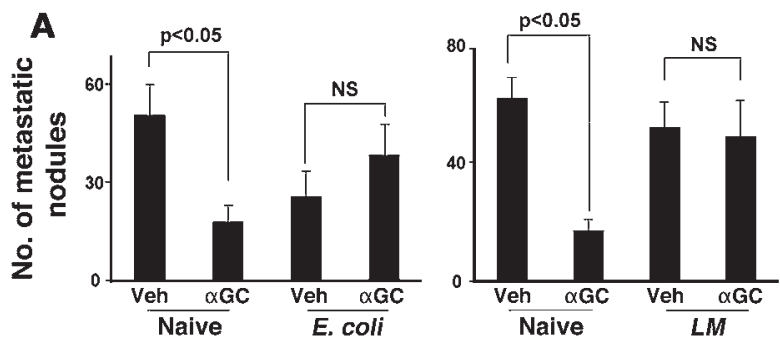

B

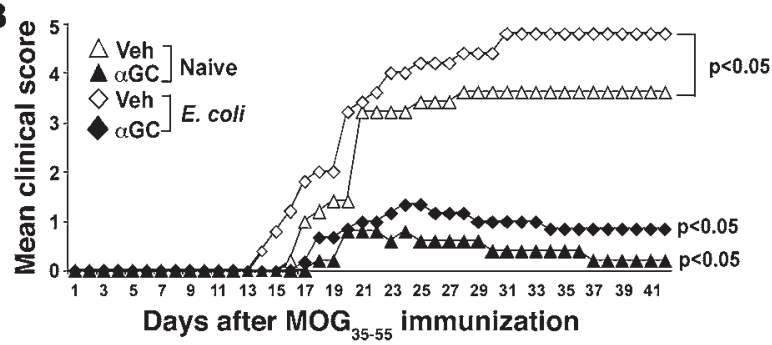


order to normalize numbers of iNKT cells in the subsequent culture with isolated splenic DCs. For splenic iNKT cells, single-cell suspensions of splenocytes were prepared, and iNKT cells were enriched based on negative selection of B220-, CD11c-, CD62L-, Gr-1-, and CD11b-expressing cells by magnetic sorting (Miltenyi Biotec) according to the manufacturer's protocol. The enriched cells were then labeled with CFSE and cocultured with $\alpha$-GalCer-loaded DCs as described above.

CFSE dilution analysis. Total splenocytes or enriched iNKT cells were labeled with $1 \mu \mathrm{M}$ CFSE for 15 minutes at $37^{\circ} \mathrm{C}$ in PBS containing $5 \%$ FCS and washed twice with R-10 medium. Labeled splenocytes $\left(2 \times 10^{5}\right.$ cells per well) were then stimulated with $\alpha$-GalCer $(100 \mathrm{ng} / \mathrm{ml})$ with or without addition of IL-2 $(10 \mathrm{ng} / \mathrm{ml})$ in the culture media or stimulated with purified $\alpha$-GalCer-loaded DCs for 24 hours in R-10 medium. Cells were washed 3 times with R-10 medium and cultured for an additional 96 hours in R-10 medium without $\alpha$-GalCer. At the end of the culture, cells were harvested, stained with PE-labeled CD1d tetramer and anti-B220PerCP, and analyzed by flow cytometry. Dead cells were excluded from the analysis by electronic gating. CFSE dilution analysis was performed on B220-tetramer ${ }^{+}$iNKT cells.

Assessment of ConA-induced hepatitis. ConA (350 $\mu \mathrm{g}$ in $200 \mu \mathrm{l}$ PBS) was injected i.v. into mice. Mice were sacrificed 24 hours later, and serum was collected and analyzed for ALT levels using Prochem V (Drew Scientific) according to the manufacturer's protocol.

Determination of lung metastases of B16 melanoma. B6 mice were injected i.v. with $3 \times 10^{5}$ syngeneic B16 melanoma cells suspended in PBS. Mice were treated with $\alpha$-GalCer ( $5 \mu$ g per injection) or vehicle at 0,4 , and 8 days. Fifteen days after challenge, mice were sacrificed, lungs were removed, and the number of metastatic nodules was counted as described previously (49).

Induction and evaluation of EAE. Mice were immunized s.c. with $200 \mu \mathrm{g}$ of $\mathrm{MOG}_{35-55}$ peptide (Bio-Synthesis Inc.) emulsified in CFA (BD Biosciences) on day 0 and in incomplete Freund's adjuvant on day 7 , as described previously (43). Mice also received $250 \mathrm{ng}$ of pertussis toxin (Invitrogen) i.p. on days 0 and 2 . Mice were treated with $5 \mu \mathrm{g}$ of $\alpha$-GalCer or vehicle on days 0,4 , and 7 by i.p. injection. Clinical symptoms were monitored daily after the first immunization. The clinical score was graded as follows: 0 , no disease; 1 , tail limpness; 2 , hind-limb weakness; 3 , hind-limb paraly- sis; 4 , forelimb weakness; 5 , quadriplegia; and 6 , moribund. Mice were sacrificed at grade 6 .

Statistics. Statistical significance between 2 groups was determined by application of an unpaired 2-tailed Mann-Whitney $U$ test. A $P$ value less than 0.05 was considered significant. Statistical significance between multiple groups was determined by application of ANOVA followed by Bonferroni post-hoc test for samples determined to approximate normal distribution by Kolmogorov-Smirnov normality test with Dallal-Wilkinson-Lilliefor $P$ value. When samples were determined not to approximate normal distribution, Kruskal-Wallis followed by Dunn's post-hoc test was used instead. A $P$ value less than 0.05 was considered significant for the multiple comparison tests.

\section{Acknowledgments}

We wish to thank Kirin Brewery Co. for providing $\alpha$-GalCer; Laura E. Gordy and S. Joyce for providing CD1d tetramers used in some of the initial experiments; Yi-Wei Tang for multiple bacterial organisms; Roy Curtiss for S. typhimurium $\chi 4550$; and Hao Shen for $L$. monocytogenes. We also thank Sebastian Joyce for helpful discussions and critical reading of the manuscript and Chyung-Ru Wang for helpful discussions and sharing of data prior to publication. This work was supported by NIH grants AI50953, NS44044, and HL68744 (to L. Van Kaer), the American Diabetes Association (to L. Wu), and by a postdoctoral fellowship from the National Multiple Sclerosis Society of America (to V.V. Parekh).

Received for publication June 22, 2007, and accepted in revised form March 12, 2008.

Address correspondence to: Luc Van Kaer, Department of Microbiology and Immunology, Vanderbilt University School of Medicine, Medical Center North, Room A-5301, Nashville, Tennessee 37232, USA. Phone: (615) 343-2707; Fax: (615) 343-2972; E-mail: luc.van.kaer@vanderbilt.edu.

Sungjune Kim and Saif Lalani contributed equally to this work.
1. Taniguchi, M., Harada, M., Kojo, S., Nakayama, T., and Wakao, H. 2003. The regulatory role of Vo14 NKT cells in innate and acquired immune response. Annu. Rev. Immunol. 21:483-513.

2. Brigl, M., and Brenner, M.B. 2004. CD1: antigen presentation and T cell function. Annu. Rev. Immu nol. 22:817-890.

3. Kronenberg, M. 2005. Toward an understanding of NKT cell biology: progress and paradoxes. Annu. Rev. Immunol. 23:877-900.

4. Van Kaer, L. 2007. NKT cells: T lymphocytes with innate effector functions. Curr. Opin. Immunol. 19:354-364.

5. Bezbradica, J.S., Van Kaer, L., and Joyce, S. 2007. Natural killer T cells. In Encyclopedia of life sciences. John Wiley \& Sons, Ltd. http://www.els.net.

6. Bendelac, A., Savage, P.B., and Teyton, L. 2007. The biology of NKT cells. Annu. Rev. Immunol. 25:297-336.

7. Godfrey, D.I., MacDonald, H.R., Kronenberg, M., Smyth, M.J., and Van Kaer, L. 2004. NKT cells: what's in a name? Nat. Rev. Immunol. 4:231-237.

8. Brutkiewicz, R.R. 2006. CD1d ligands: The good, the bad, and the ugly. J. Immunol. 177:769-775.

9. Kinjo, Y., et al. 2005. Recognition of bacterial glycosphingolipids by natural killer T cells. Nature. 434:520-525.

10. Mattner, J., et al. 2005. Exogenous and endogenous glycolipid antigens activate NKT cells during microbial infections. Nature. 434:525-529.
11. Sriram, V., Du, W., Gervay-Hague, J., and Brutkiewicz, R.R. 2005. Cell wall glycosphingolipids of Sphingomonas paucimobilis are CD1d-specific ligand for NKT cells. Eur. J. Immunol. 35:1692-1701.

12. Kinjo, Y., et al. 2006. Natural killer T cells recognize diacylglycerol antigens from pathogenic bacteria. Nat. Immunol. 7:978-986.

13. Kronenberg, M., and Gapin, L. 2007. Natural killer T cells: Know thyself. Proc. Natl. Acad. Sci. U. S. A. 104:5713-5714.

14. Van Kaer, L. 2004. Natural killer T cells as targets for immunotherapy of autoimmune diseases. Immunol. Cell Biol. 82:315-322.

15. Parekh, V.V., Lalani, S., and Van Kaer, L. 2006. The in vivo response of invariant natural killer T cells to glycolipid antigens. Int. Rev. Immunol. 26:31-48.

16. Wilson, M.T., et al. 2003. The response of natural killer T cells to glycolipid antigens is characterized by surface receptor down-modulation and expansion. Proc. Natl. Acad. Sci. U. S. A. 100:10913-10918.

17. Crowe, N.Y., et al. 2003. Glycolipid antigen drives rapid expansion and sustained cytokine production by NKT cells. J. Immunol. 171:4020-4027.

18. Harada, M., et al. 2004. Down-regulation of the invariant V $\alpha 14$ antigen receptor in NKT cells upon activation. Int. Immunol. 16:241-247.

19. Parekh, V.V., et al. 2005. Glycolipid antigen induces long-term natural killer $\mathrm{T}$ cell anergy in mice. J. Clin. Invest. 115:2572-2583.

20. Ulrich, A.P., et al. 2005. NKT cell stimulation with glycolipid antigen in vivo: costimulation-dependent expansion, bim-dependent contraction, and hyporesponsiveness to further antigenic challenge. J. Immunol. 175:3092-3101.

21. Ikarashi, Y., et al. 2005. Phenotypical and functional alterations during the expansion phase of invariant V $\alpha 14$ natural killer $\mathrm{T}$ (V $\alpha 14 \mathrm{i}$ NKT) cells in mice primed with $\alpha$-galactosylceramide. Immunology. 116:30-37.

22. Bezbradica, J.S., et al. 2005. Distinct roles of dendritic cells and B cells in Va14Ja18 natural T cell activation in vivo. J. Immunol. 174:4696-4705.

23. Tupin, E., Kinjo, T., and Kronenberg, M. 2007. The unique role of natural killer $\mathrm{T}$ cells in the response to microorganisms. Nat. Rev. Microbiol. 5:405-417.

24. Moody, D.B. 2006. TLR gateways to CD1 function. Nat. Immunol. 7:811-817.

25. Brigl, M., Bry, L., Kent, S.C., Gumperz, J.E., and Brenner, M.B. 2003. Mechanism of CD1d-restricted natural killer $\mathrm{T}$ cell activation during microbial infection. Nat. Immunol. 4:1230-1237.

26. Van Kaer, L., and Joyce, S. 2005. Innate immunity: NKT cells in the spotlight. Curr. Biol. 15:R429-R431.

27. Paget, C., et al. 2007. Activation of invariant NKT cells by toll-like receptor 9 -stimulated dendritic cells requires type I interferon and charged glycosphingolipids. Immunity. 27:597-609.

28. Feuillet, V., et al. 2006. Involvement of Toll-like receptor 5 in the recognition of flagellated bacteria. Proc. Natl. Acad. Sci. U. S. A. 103:12487-12492. 
29. Kitamura, H., et al. 1999. The natural killer T (NKT) cell ligand $\alpha$-galactosylceramide demonstrates its immunopotentiating effect by inducing interleukin (IL)-12 production by dendritic cells and IL-12 receptor expression on NKT cells. J. Exp. Med. 189:1121-1128.

30. Takeda, K., et al. 2000. Critical contribution of liver natural killer T cells to a murine model of hepatitis. Proc. Natl. Acad. Sci. U. S. A. 97:5498-5503.

31. Nagarajan, N.A., and Kronenberg, M. 2007. Invariant NKT cells amplify the innate immune response to lipopolysaccharide. J. Immunol. 178:2706-2713.

32. Lin, Y., Roberts, T.J., Wang, C.R., Cho, S., and Brutkiewicz, R.R. 2005. Long-term loss of canonical NKT cells following an acute virus infection. Eur. J. Immunol. 35:879-889.

33. Halder, R.C., Aguilera, C., Maricic, I., and Kumar, V. 2007. Type II NKT cell-mediated anergy induction in type I NKT cells prevents inflammatory liver disease. J. Clin. Invest. 117:2302-2312.

34. Osman, Y., et al. 2000. Activation of hepatic NKT cells and subsequent liver injury following administration of $\alpha$-galactosylceramide. Eur. J. Immunol. 30:1919-1928.

35. Ito, K., et al. 2000. Involvement of decidual V $\alpha 14$ NKT cells in abortion. Proc. Natl. Acad. Sci. U. S. A 97:740-744.

36. Major, A.S., Joyce, S., and Van Kaer, L. 2006. Lipid metabolism, atherogenesis and CD1-restricted antigen presentation. Trends Mol. Med. 12:270-278.

37. Bilenki, L., Yang, J., Fan, Y., Wang, S., and Yang, X. 2004. Natural killer T cells contribute to airway eosinophilic inflammation induced by ragweed through enhanced IL-4 and eotaxin production. Eur. J. Immunol. 34:345-354.

38. Motsinger, A., et al. 2002. CD1d-restricted human natural killer $\mathrm{T}$ cells are highly susceptible to human immunodeficiency virus 1 infection. J. Exp. Med. 195:869-879.

39. Sandberg, J.K., Bhardwaj, N., and Nixon, D.F. 2003. Dominant effector memory characteristics, capacity for dynamic adaptive expansion, and sex bias in the innate Vo24 NKT cell compartment. Eur. J. Immunol. 33:588-596.

40. Snyder-Cappione, J.E., et al. 2007. Individuals with pulmonary tuberculosis have lower levels of circulating CD1d-restricted NKT cells. J. Infect. Dis. 195:1361-1364.

41. Van Kaer, L. 2005. $\alpha$-Galactosylceramide therapy for autoimmune diseases: prospects and obstacles. Nat. Rev. Immunol. 5:31-42.

42. Smyth, M.J., et al. 2002. Sequential production of interferon- $\gamma$ by NK1.1 $1^{+} \mathrm{T}$ cells and natural killer cells is essential for the antimetastatic effect of $\alpha$-galactosylceramide. Blood. 99:1259-1266.

43. Singh, A.K., et al. 2001. Natural killer T cell activation protects mice against experimental autoimmune encephalomyelitis. J. Exp. Med. 194:1801-1811.

44. Jahng, A.W., et al. 2001. Activation of natural killer $\mathrm{T}$ cells potentiates or prevents experimental autoimmune encephalomyelitis. J. Exp. Med. 194:1789-1799.

45. Furlan, R., et al. 2003. Activation of invariant NKT cells by $\alpha$-GalCer administration protects mice from MOG35-55 induced EAE: critical roles for administration route and IFN- $\gamma$. Eur. J. Immunol. 33:1830-1838.

46. Bezbradica, J.S., Stanic, A.K., and Joyce, S. 2006. Characterization and functional analysis of mouse invariant natural T (iNKT) cells. Curr. Prot. Immunol. 14.13.1-14.13.27.

47. Andersen-Nissen, E., Smith, K.D., Bonneau, R., Strong, R.K., and Aderem, A. 2007. A conserved surface on Toll-like receptor 5 recognizes bacterial flagellin. J. Exp. Med. 204:393-403.

48. Parekh, V.V., et al. 2004. Quantitative and qualitative differences in the in vivo response of NKT cells to distinct $\alpha$ - and $\beta$-anomeric glycolipids. J. Immunol. 173:3693-3706.

49. Fujii, S., Shimizu, K., Kronenberg, M., and Steinman, R.M. 2002. Prolonged IFN- $\gamma$-producing NKT response induced with $\alpha$-galactosylceramide-loaded DCs. Nat. Immunol. 3:867-874. 